\title{
THE OLDER NURSE IN THE WORKPLACE RETENTION OR RETIREMENT
}

\author{
by \\ Samantha Powell \\ A thesis submitted to the Victoria University of Wellington \\ in partial fulfilment of the \\ requirements for the degree of \\ Master of Arts (Applied) \\ in Nursing
}

Victoria University of Wellington

2010 


\begin{abstract}
The nursing workforce, as with other health professionals, is aging with $50 \%$ aged over 47 years. In combination with predictions of continuing nursing workforce shortages, an aging population and increasingly complex health environment, this presents a unique set of challenges to the healthcare sector as both the population and nursing workforce continue to age. A review of the international literature suggests that the majority of older nurses in the workplace (50 years and over), are highly experienced and have extensive knowledge and practice wisdom from their years of nursing. What is also clear is that the current environment does not always support this cohort of nurses and that they often feel less valued. As a consequence, in a time of unprecedented shortages, we are at risk of losing this valuable experience from the workplace prematurely. Some suggested strategies to support this group of nurses include consideration of health and safety issues, flexibility with rosters and shift pattern, options for part time work, continuing professional development and ensuring their experience and knowledge continues to be valued in the work place.
\end{abstract}

This research was carried out to explore the understanding of the issues facing the older nurse in a New Zealand context. There is a significant gap in literature as to the experience in the workplace of older nurses in New Zealand. In relation to health workforce retention, strategies are described from a general workforce perspective. Specific strategies in relation to the retention of the older nurse are not addressed or described. The international literature describes both the older nurses' experiences and strategies that can be used to retain them in the workforce, which have relevance to the local healthcare environment. Using a descriptive survey design two groups of Clinical/Charge Nurse Managers in two separate District Health Boards were asked about their awareness of the issues facing older nurses and what strategies they were using to address them. It was the assumption that as a group they were very aware of the issues facing older nurses and were often using informal strategies in an attempt to retain this group of nurses. 
The aim of this research was to raise awareness of the needs of the older nurse in the workplace and to capture and describe the strategies being used.

Results indicated that indeed the Clinical/Charge Nurse Managers were very aware of the issues facing older nurses in the workplace and were innovative in their attempts to retain them in the workplace, and these retention strategies were similar to those discussed in the international literature. The need for national direction and organisational policy in place to support the Clinical/Charge Nurse Managers' retention efforts was also raised in the literature and I believe also needs consideration in the New Zealand context.

Key words: Older nurse, workforce, retention 


\section{Acknowledgements}

I had often heard the word journey used in relation to undertaking a thesis, I now have a clearer understanding of why, this has been somewhat of an extended journey for me with different key people accompanying me for a portion of the journey then moving to another path. Firstly I would like to thank the participants who took the time out of their very busy jobs to participate in the research, your honest and insightful words have enriched the research and reinforced for me the importance of nursing leadership roles in our profession. Secondly I want to acknowledge the nursing role models that have helped shape and influence my nursing pathway, particularly to my Mother Jackie Powell, Nanette Ainge and Sue Hayward.

To my supervisors (plural). Thanks to Dr Rose McEldowney for getting me started and your understanding when I thought it was a good idea to change careers and move cities at the same time. To Dr Chris Walsh, thank you for your honesty and support in re-energising me again, who would have thought I would get to first draft. And for the ending thanks to Dr Pamela Wood, your feedback and attention to detail has seen me reach this point. A special thanks to Jane Hardcastle for her support both personally and professionally, and the provision of some extremely timely feedback that has enabled me to complete this thesis. I also wish to acknowledge my employers for their support during my Masters journey.

To my family and friends, thank you for your support, understanding and encouragement and finally to Mark, thanks for your support and belief that I could get to this point. 


\section{Table of Contents}

\section{Preliminary Pages}

Abstract

Acknowledgements...............................................................................

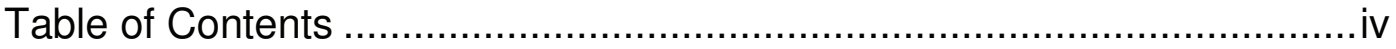

List of Appendices ............................................................................

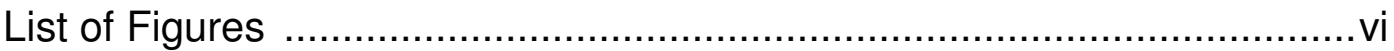

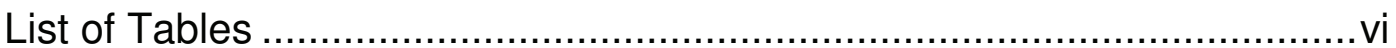

\section{Chapter One: Introduction to the Study}

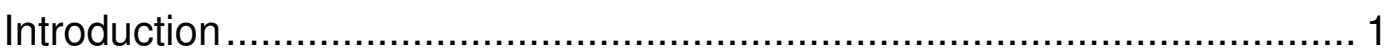

The New Zealand Healthcare Environment ......................................... 3

The Research Question .................................................................. 5

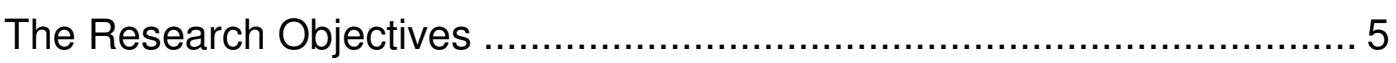

Thesis Structure ............................................................................. 6

\section{Chapter Two: Literature Review}

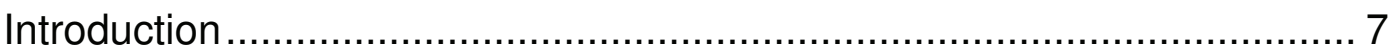

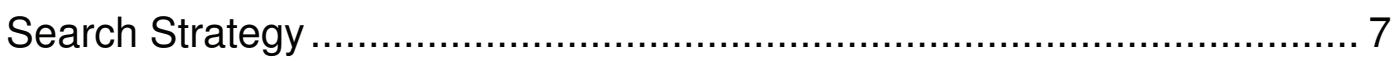

The Future Health Workforce............................................................ 8

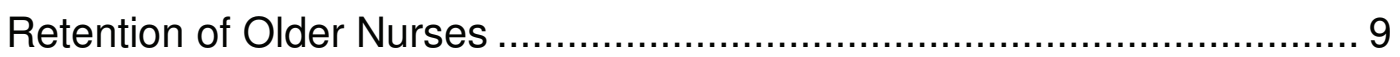

Age Discrimination and the Older Nurse ........................................... 13

Generational Tensions................................................................ 15

Line Manager Behaviour and Retention ............................................ 18

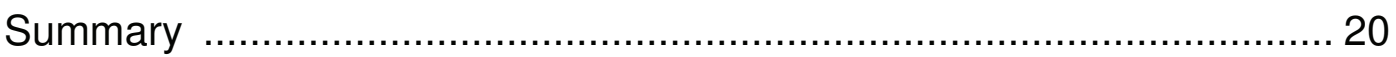

\section{Chapter Three: Methodology}

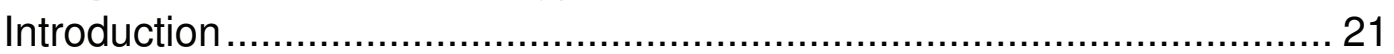

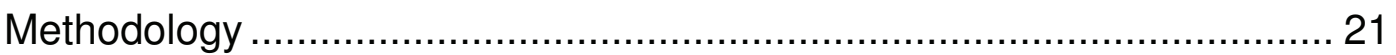

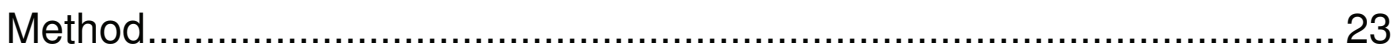

Research Question ..................................................................... 23

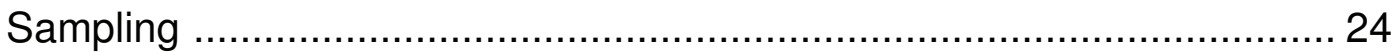

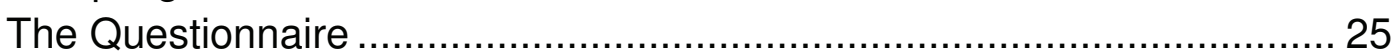

Adaption of the Survey ................................................................. 27

Validity and Reliability ................................................................ 27

Treaty of Waitangi Considerations................................................... 30

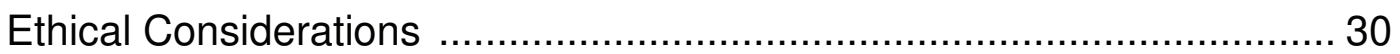

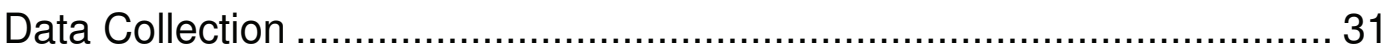

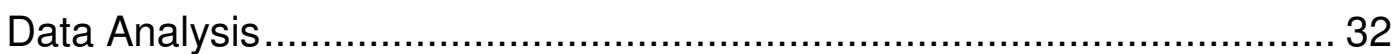

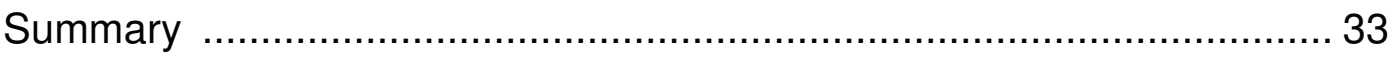




\section{Chapter Four: Findings}

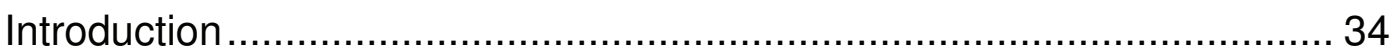

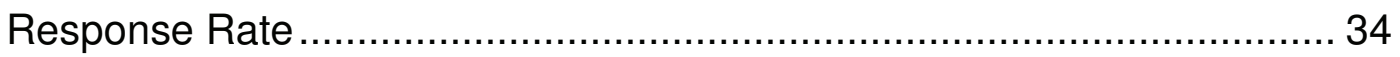

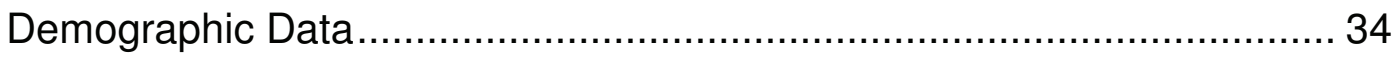

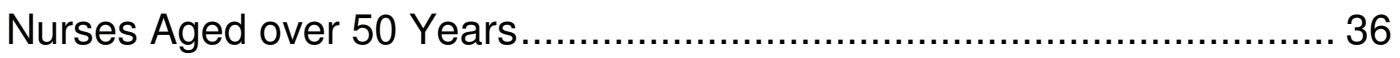

Awareness of Needs of Older Nurses ................................................. 37

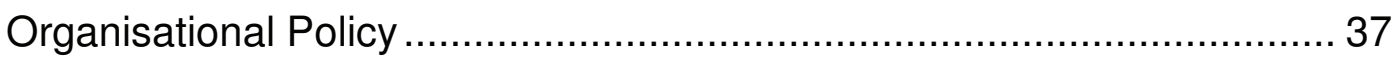

Responsibility to Retain Older Nurse ……........................................... 37

Strategies to Retain Older Nurse ……………….............................. 38

Impact of Not Retaining Older Nurses in the Workforce .......................... 39

Strengths of the Older Nurse ......................................................... 40

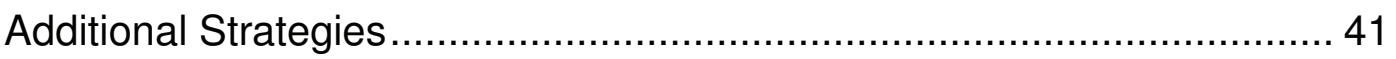

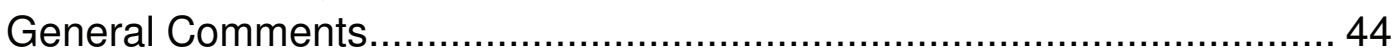

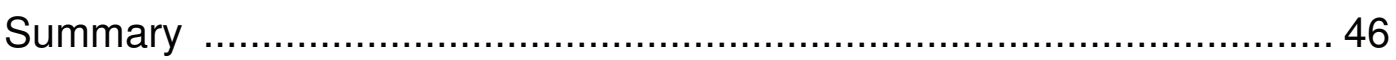

\section{Chapter Five: Discussion}

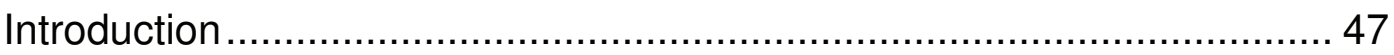

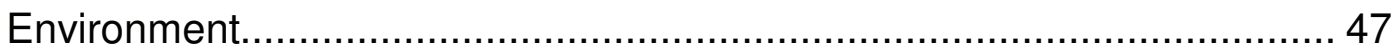

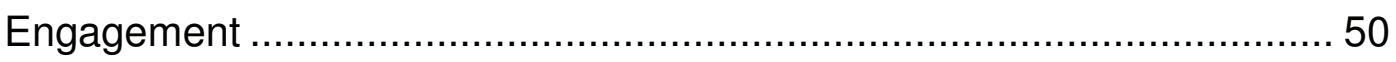

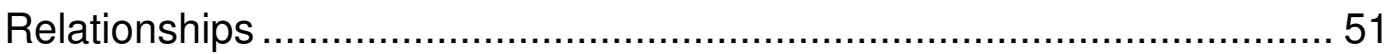

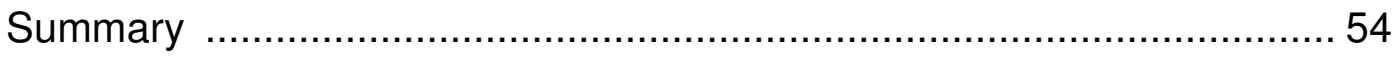

Chapter Six: Limitations, Recommendations and Conclusion

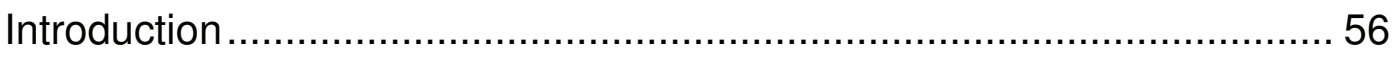

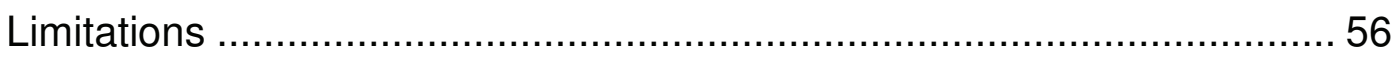

Implications for Practice............................................................... 57

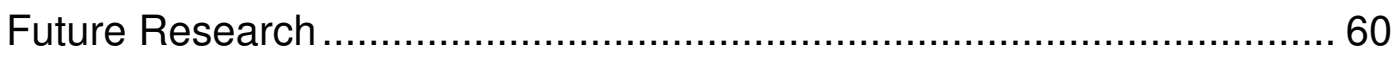

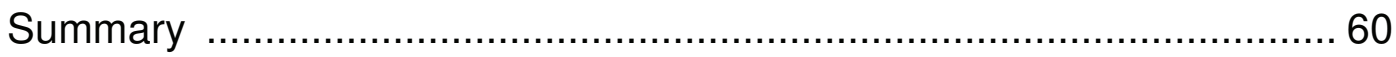

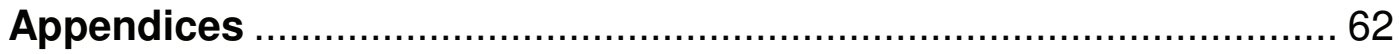

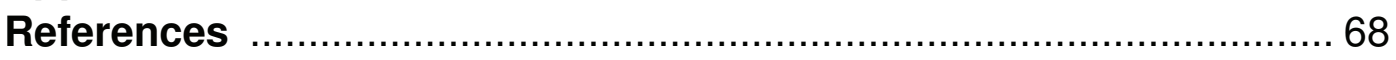




\section{Appendices}

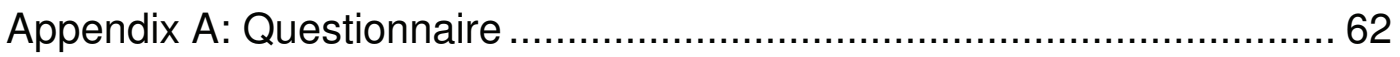

Appendix B: Permission to use/and or adapt survey tool.......................... 65

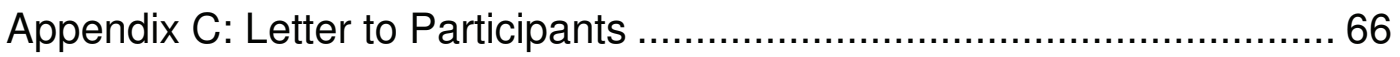

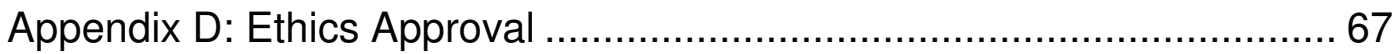

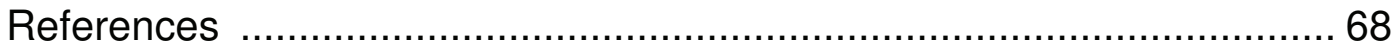

\section{List of Figures}

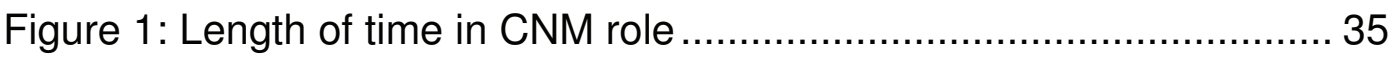

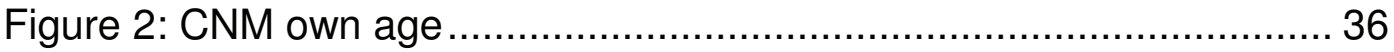

\section{List of Tables}

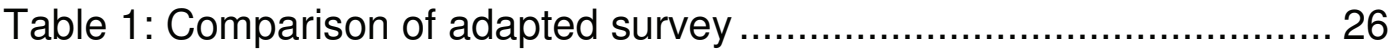

Table 2: Percentage of total staff aged fifty and over.............................. 36

Table 3: Awareness of needs of older nurses......................................... 37

Table 4: Responsibility for retaining the older nurse ................................ 38

Table 5: Stategies to retain the older nurse ........................................... 39

Table 6: Impact of not retaining older nurses in the workforce ................. 39 


\section{Chapter One: Introduction to the Study}

\section{Introduction}

International research suggests that older nurses are struggling in the workplace and are often staying for financial reasons, sometimes to the detriment of their health (Cohen, 2006). There is a significant amount of research, particularly from North America and the United Kingdom exploring the older nurse's experience in the work place and retention strategies identified to support this cohort of nurses (Andrews, Manthorpe, \& Watson, 2005; Arnold, 2008; Bennett, Davey, \& Harris, 2009; Buerhaus et al., 2005; Camerino et al., 2006; Cohen, 2006; Cyr, 2005; Fitzgerald, 2007; Hader, Saver, \& Steltzer, 2006; Hatcher et al., 2006; McHaney \& Varner, 2006; Mion et al., 2006; Norman et al., 2005; Letvak, 2002a, 2002b, 2003; Piktialis, 2007; Reineck \& Furino, 2005; Santos et al., 2003; Sherrod, 2006; Watson, Manthorpe, \& Andrews, 2003). To date this has not been explored widely in a New Zealand context. Retention of the older nurse will be a key strategy as the predicted health workforce shortages begin to impact on the healthcare environment. This environment has seen significant change including an increase in work intensity, more emphasis on professional responsibilities and competency-based frameworks with ongoing education requirements. Not enough is known about the experiences of older nurses in the New Zealand healthcare setting and what impact the current environment may have on their decisions to leave the workforce. I work in a senior nursing position where one of my key responsibilities is to maintain capability and capacity of the nursing workforce within my organisation. This has increased my need to understand and perhaps challenge some of the assumptions that are made about the older nursing workforce and to investigate what can be done at a strategic and operational level to support and retain the older nurse. Finally, I wanted to explore from a New Zealand perspective what kind of environment could provide support and retain the older nurse in the workforce. 
One of the key changes to the healthcare environment in which the older nurse practices was the introduction in 2004 of the Health Practitioners Competence Assurance (HPCA) Act 2003. Under the Act nurses must now demonstrate their ongoing competency to practise. The Nursing Council of New Zealand (NCNZ) is responsible for monitoring ongoing nursing competency which they achieve by randomly auditing $5 \%$ of the nursing workforce during the annual practising certificate renewal process. Following the introduction of the Act and in my role at the time as a nurse educator, I provided education and support to nurses who were being audited by NCNZ. It was my observation that the portion of the nursing workforce who found this the most challenging were older nurses. Some sensitivity is required when defining people by age, but the international literature relating to this consistently describes an older nurse as one aged 50 years and over (Andrews et al., 2005; Buerhaus et al., 2005; Cohen, 2006; Crocker Houde, \& Devereaux, Melillo, 2009; Cyr, 2005; Fox \& Abrahamson, 2009; Hatcher et al., 2006; Watson et al., 2003).

When nurses from this age group would come to see me, the first visit was often about dealing with the emotion that the audit had raised for them, which could range from anger through to fear. What impacted on me the most was the fear and the vulnerability some of these nurses were expressing. This group raised several questions. Is it (the audit) worth it? Is it time for me to go? Will I lose my job? I have been fortunate in my nursing career to have some strong older nurses as role models and I was left wondering why these older nurses felt so vulnerable and undervalued.

Perhaps the current New Zealand healthcare environment is not giving enough consideration to the retention of the older nursing workforce. The "baby boomer bulge" (Davey, 2003, p.156) means that the nurses aged over 50 are a significant portion of our nursing workforce. Key national initiatives such as Nursing Entry to Practice programmes $(\mathrm{MOH}, 2010)$ developed with the purpose of growing and retaining newly registered nurses in New Zealand have begun to address future workforce requirements but will not replace the nurses from the baby boomer generation. 


\section{The New Zealand health care environment}

New Zealand is a small country in the South Pacific, with a population of just over four million people. New Zealand is a diverse multicultural nation with the indigenous Maori people forming about $15 \%$ of the population. The majority of the population live in cities and the minority are widely dispersed in rural areas (Statistics New Zealand, 2009). As a nation our population is growing slowly, becoming more ethnically diverse and also aging. We enjoy comparable health status with other Organisation for Economic Co-operation and Development (OCED) countries and spend similar amounts of our Gross Domestic Product (GDP) on health. Our life expectancy has risen over the last 50 years, but there remain disparities in life expectancy based on ethnic and socioeconomic differences. From central government the Minister of Health has overall responsibility for the health and disability support system. There is a predominantly publicly funded health and disability sector divided into 21 separate district health boards (DHBs) that provide health care services from a range of providers including public hospitals, non-profit health agencies, iwi (Maori tribe) groups or private organisations (Ministry of Health, 2006).

Projections for the future indicate that our population will continue to grow slowly and also age. According to the 2007 Census almost half of the New Zealand workforce is aged over 40. This aging trend as Davey (2003) suggests is set to continue and by 2020 New Zealand may well be experiencing a negative growth in the labour force. The Ministry of Health further supports this by stating that "the most significant change facing the New Zealand labour market over the next 25 years is that many more workers will retire than will be recruited" $(2006$, p.6). The future may be one where we face significant labour shortages. Davey introduces the concept of human capital when describing our current workforce, suggesting that looking to the future we must improve our human capital by maximising the potential of the older workforce. Davey asserts that "if those in mid-life are unable to contribute their full economic capacity due to unemployment, underemployment, premature retirement, discrimination 
or other circumstances, this has implications for their individual futures, for business enterprise and for society as a whole" (p.156).

As a population ages, demands on the health and disability sector increase. Technological and medical advances have improved health status, but this means greater community expectations about the right and access to appropriate health care (Ministry of Health, 2006). One of the challenges to the health and disability sector in New Zealand is to ensure that an adequately prepared health workforce is in place to meet the future demands of the changing population. Attempts have been made over the last decade to accurately describe the current health and disability workforce with varying degrees of success. Data from the Health Workforce Advisory Committee (HWAC), the New Zealand Institute of Economic Research (NZIER), and District Health Boards of New Zealand (DHBNZ) estimate our health and disability workforce to number approximately 100,000 . Of that number around 67,000 are said to be registered health professionals (those registered under the HPCA Act 2003) including nurses, midwives, doctors and allied health professionals. The remaining 33,000 are support workers and alternative and complementary health workers.

Of those 67,000 , it is estimated that 42,662 are registered nurses (NCNZ, 2010). The nursing workforce as with other health professionals is an aging one with $50 \%$ aged over 47 years (Health Workforce Information Programme (HWIP), 2009). With a significant portion of the registered nurses approaching retirement within the next 15-20 years, future workforce predictions suggest that there will not be sufficient nurses to replace them (Alpass \& Mortimer, 2007). Maximising the potential of the older nursing workforce will be a key strategy in maintaining our health system into the future. Research conducted in North America and the United Kingdom (UK) (Andrews et al., 2005; Camerino et al., 2006; Cyr, 2005; Fitzgerald, 2007; Hader, Saver, \& Steltzer, 2006; Hatcher et al., 2006; Letvak, 2002a; Letvak, 2003; McHaney \& Varner, 2006; Mion et al., 2006; Watson, 2003) suggests that we are not doing enough to retain the older nursing workforce. Employers are sometimes aware of the issues 
facing older nurses in the workplace but do not have systems or policies in place to address the issues and support the older nurse. As important as it is to grow a nursing workforce for the future, retaining the knowledge and experience in our current workforce for as long as we can is equally as important.

Emerging from the literature, the person described as most likely to influence an older nurse's decision making in relation to continued meaningful employment is the nurse's direct line manager (Anthony et al., 2005; Cohen, 2006; Hu, Herrick, \& Hodgin, 2004; Kupperschmidt, 2006; Letvak, 2002a; Norman et al., 2005; Weick, 2007). The term line manager in the context of this research is the Clinical or Charge Nurse Manager. The position title and role descriptor of the Clinical Nurse Manager (CNM) or Charge Nurse Manager (CNM), in a District Health Board setting was scoped and endorsed at a national level in New Zealand in 2007 following the 2006 nursing and midwifery Multi Employee Collective Agreement (MECA). The term is used interchangeably and has the same role descriptor. It was the individual DHB's choice as to the title used. In most hospital settings a registered nurse's direct line manager is a CNM. From personal observation and experience, I anticipated that the CNM group would be very aware of the issues facing older nurses, and in addition I also anticipated that they would have some successful strategies that could be utilised on a more formal basis. This guided the development of my research question.

\section{The research question}

Are Clinical/Charge Nurse Managers aware of the issues facing older nurses in the workplace and do they utilise strategies aimed at retaining older nurses?

\section{Research objectives}

1. To identify CNMs awareness of the issues facing older nurses in the workforce.

2. To describe CNMs responses to strategies identified in the international literature regarding the retention of older nurses. 
3. To elicit the strategies CNMs currently use to retain older nurses.

A descriptive survey was selected as an appropriate method to gain insight into the views of New Zealand CNMs in two large DHBs in relation to the issue of retention of older nurses. The survey asked for demographic information related to the CNM group being surveyed including their own age and length of time in a CNM role, and the percentage of staff in their clinical area aged over 50 years of age. It sought their awareness of the needs of older nurses, whether policy existed in their organisation to address the needs of the older nursing workforce and who they saw as being responsible for retention. Suggested strategies for retention were presented and feedback sought on their usefulness, and an opportunity was given for additional strategies to be outlined. Finally the CNMs were asked what they saw as the strengths of the older nurse.

\section{Thesis structure}

Chapter Two provides a comprehensive review of the contemporary literature in relation to the research topic. The older nurse is discussed in relation to the future workforce requirements, key retention factors, ageism and generational context. The role of the direct line manager in relation to retention of older nurses is explored in the final part of the literature review chapter. Chapter Three provides an overview of the research method and design. Adaptation of the survey for the study context is discussed. In addition validity, reliability, methods of data collection and analysis are outlined along with Treaty of Waitangi and ethical considerations. Descriptive statistics and thematic analysis are utilised to present findings from the data in Chapter Four. Research findings are discussed in relation to the literature and presented in Chapter Five. As a framework for discussion three main themes are used: environment, engagement and relationships. Chapter Six provides an overview of the limitations of the research and implications for practice, including organisational policy, CNM support, education for generational understanding and age discrimination, health and safety and work intensity and value of older nurses. To conclude, the potential for future research is outlined. 


\section{Chapter Two: Literature Review}

\section{Introduction}

Contemporary literature indicates that challenges concerning the retention of older nurses in the workforce are complex and ongoing. Nonetheless, these challenges are related to a number of commonly established issues. To present what is known about these issues this review is grouped into five prominent themes: future health workforce, retention of older nurses, age discrimination and the older nurse, generational tensions and line manager behaviour and retention. This chapter sets the scene for this study and explores what is known about some of the challenges that both an aging population and nursing workforce present to individual nurses, the nursing workforce and the wider health care sector. Understanding the impact that the changing healthcare environment may have on the cohort of nurses currently aged 50 and over as they begin to consider retirement is an important issue facing the healthcare sector, if these nurses are to be retained in the workplace. The true impact of the potential retirements in the context of an aging population and a rapidly changing health care environment remains largely unknown. Aiken, Buchan, Sochalski, Nichols and Powell (2004) suggest that the predicted shortage of nurses will have a far-reaching global impact.

\section{Search strategy}

The literature search involved accessing commonly used health databases including Medline, Cumulative Index to Nursing and Allied Health Literature (CINAHL), Proquest and Google Scholar. Local sites such as the Ministry of Health and Department of Labour websites were also utilised to establish local policy and data. The search was limited to publications between 1998 - 2009 and those published in English. The key words used for the search included nurses, older nurse, aging workforce, nursing shortage, retention of nurses, nursing job satisfaction, nursing retirement and intergenerational workforce. Individual terms and combinations were used to enable a broader search. Reference lists from all primary search articles were also utilised in order to locate relevant and 
key literature. The search strategy captured reviews and research that focused on the aging workforce, health workforce labour shortage, retention of older registered nurses (aged 50 and over), intergenerational factors and line manager behaviour in relation to retention. Researchers and policy makers from North America and the UK have been actively considering and researching the nursing workforce shortage and the retention of older nurses particularly over the last 10 years. Unfortunately there is limited research on the nursing workforce shortage and the retention of the older nurse from a New Zealand perspective.

\section{The future health workforce}

Hatcher et al. (2006) predict a global picture of an aging population, an aging workforce and a total workforce capacity that will be diminishing. The post World War Two period saw a dramatic increase in fertility rates and the creation of the baby boomer generation (those born 1941 -1960). This generation is already beginning to reach retirement age. Since the baby boomer generation, fertility rates have progressively declined yet people in this generation are predicted to live longer. According to Hatcher et al. the average baby boomer will live 18 years past their retirement age. In a more global context Alpass \& Mortimer (2007) claim that over the last 25 years, in OCED countries, 45 million workers entered retirement. This workforce was replaced by 120 million baby boomers. In the next 25 years it is predicted that 70 million of the baby boomers will enter retirement and be replaced by only 5 million entering the workforce. From a health care and provision perspective this presents cause for concern, suggesting that demand for healthcare workers is likely to exceed supply.

New Zealand, along with other OCED countries, is facing a severe health workforce crisis. Currently the regulated health workforce (those legislated under the HPCA Act, 2003) numbers approximately 67,000 (Meates, 2007). The deficit predicted is in the region of 7,000 to 10,000 regulated health workers by 2011 and 18,000 to 28,000 by 2021 (Alpass \& Mortimer, 2007). Contributing to this crisis are the predictions that between 2001 and 2021 the New Zealand population aged over 65 will increase from 461,000 
to 729,000 , and most significantly, the population aged over 85 is predicted to grow from 48,639 to 105,400 (DHBNZ, 2007). Nurses are by far the largest workforce in the health care sector. The nursing workforce, as with other health professionals, is aging, with $50 \%$ aged over 47 years (HWIP, 2009). The combination of an aging workforce and aging population presents a significant challenge to the health sector. Coupled with predictions for unprecedented healthcare demand, the retention of our current health workforce, particularly nurses, is a significant concern requiring strategic direction. Preventing the loss of older nurses prematurely from the workforce is a significant factor influencing future workforce challenges, and as such warrants further exploration.

\section{Retention of older nurses}

Understanding the workplace, and factors influencing retention from older nurse's perspective, features in American and UK research that explores the experience of older nurses, their managers, employers, human resources and policy makers. In a UK study Andrews et al. (2005) identified some common factors influencing older nurse's decisions to leave the workplace including "pace of technological change and stress in the workplace" (p.302). Further, they identified factors influencing their decisions to stay at work including "flexible working hours and financial considerations" (p. 303). In another UK study Cyr (2005) also identified factors that influence retirement of nurses. Factors influencing nurses' decisions to stay in the workplace were related to financial independence and work intensity. Seasonal employment, creative scheduling, elimination of weekend shifts and premium hourly rate were reported as attractive incentives. When discussing factors that influence early retirement, an increase in work intensity was described by half the respondents as influencing their decision to retire earlier than anticipated.

Letvak (2002a, 2002b, 2003) has been actively researching the experiences of older nurses in North America. Her qualitative studies, underpinned by a feminist relational ontology, have explored the experiences of nurses aged 50 and over. In a 2003 study she described 
nurses' reasons for staying in the workplace as being related to having positive relationships with the patients, families and the organisation. She describes a group of nurses who have a love for what they do, are confident in their abilities, yet as a generation are accepting of what they have and may be lacking in confidence to speak out in times of conflict. The impact of the newer generation of nurses and their preconceived ideas about older nurses along with the impact of a manager's behaviour is described as a significant influence on how an older nurse views her value to the organisation. Letvak (2002b) undertook a similar study in the same year specifically looking at a group of peri-operative nurses. Themes emerging from this study included nurses' concerns about aging, continuing to be of value to colleagues and the organisation and concerns about not being able to afford to retire. This study reported that, as a group, the operating room nurses were generally satisfied with their job, but they were concerned about the demands of being on call, inflexible rostering, flat wage structures that do not recognise years of service, and issues about managing the work intensity.

North American authors Mion et al. (2006) described various reasons for nurses retiring, concluding that efforts to delay and retain this group of nurses needed to be multifactorial. This commissioned report focused on one health care provider's approach to create a work environment that was focused on retaining older experienced nurses. They organised their report into four themes: the worth of older nurses, generational issues, roles for the aging nurse and ways to support the aging nurse. They then developed a multifaceted organisational approach that addressed the issues identified in the four themes. Key features of this approach included education and training for all staff, attention to work intensity for older nurses and the development of roles for older nurses to retain them in the organisation in less acute settings. This report demonstrates that a single healthcare organisation can address the issues in relation to retention of older nurses.

Camerino et al. (2006) undertook a large study exploring nurses' perceived ability to work and intention to leave in relation to their age. 
They used a representative sample across 10 European countries. In their discussion they identified that attempts to reverse the nursing shortage need to include institutional policies that sustain work ability through better working conditions and improved environment. They assert that efforts should be made to find suitable alternative nursing work for those no longer able to cope with the increased work intensity in their current work environments.

Also identified from the study by Camerino et al. (2006) was that local human resource policy in organisations and health care institutions did not reflect strategies aimed at retention of the older nursing workforce. Letvak (2002a) undertook a descriptive survey of 160 North American hospitals and 411 aged care facilities to determine the knowledge level of issues facing older nurses and plans of the clinical areas for their aging workforce. She reported that $94 \%$ of health care facilities had no policies in place to address the needs of the older nurses, and $87 \%$ had no plans to put anything in place. In her discussion, Letvak puts forward strategies for healthcare facilities to consider in relation to the needs of the older nurses, suggesting that these require organisational direction. These included assessing the job satisfaction of the existing older workforce and encouraging health care facilities to take self-responsibility with this issue. Letvak stressed the importance of not relying on federal and state government intervention to be solely responsible for addressing and implementing strategies to deal with the issues. McHaney and Varner (2006) undertook a replication study based on the study by Letvak (2002a). This study was focused in community healthcare settings in North America and asked administrators what their level of awareness was of the needs of the older nurse and what, if any, specific strategies they had in place to retain the older nurse. Nearly $78 \%$ had no plan to put policies in place.

One context in which the older nursing workforce is seen as a valuable resource is under the Magnet hospital scheme. The Magnet recognition programme is a designation or seal of approval for quality nursing and also provides a vehicle for disseminating successful practices and 
strategies among nursing systems which, in turn, attract and retain staff (Buchan, 1999; Upeinecks, 2003). Hader et al. (2006) undertook a comparison study between Magnet and non Magnet hospitals as part of a wider survey of older nurses. Overall Magnet hospitals were found to have better strategies in place for retaining an older workforce. For example, Magnet hospitals paid greater attention to ergonomic policies and lifting devices, preventive care for staff, flexibility with rosters and shift patterns and access to education and training. Other examples of strategies employed in Magnet hospitals to retain older nurses, included full benefits for part time workers and attention to creating healthy work environments. In her article Fitzgerald (2007) supports the concept of supporting older nurses to age in place, describing this as supporting the older nurse to stay and contribute in meaningful ways. Fitzgerald cites lack of attention to workplace conditions and poor human resource practice as barriers to older nurse's ability to age in place. Attention to the work environment and financial incentives are identified as ways to assist older nurses to achieve work life balance and remain in the work force.

So far the literature described suggests that if organisations want to retain older nurses they need to have the policies in place to support this. Further, organisations must pay attention to the culture of their own organisation, especially with regards to how older nurses are valued. Environments should reduce physical workload and prevent injury. Many studies highlight that the need to explore flexible responsive human resource practices, such as assistance with financial planning for retirement, phased retirement, flexible rostering, access to education and training and willingness to explore other roles for older nurses that utilise their skill and experience are of critical importance (Camerino et al., 2006; Fitzgerald, 2007; Hader et al., 2006; Letvak, 2002a; Watson, 2003).

The culture of an organisation in relation to how it values its older nursing workforce emerges from the literature. How to develop and sustain a culture that supports a nurse to age in place and enable the wisdom and experience to be utilised for as long as possible presents a challenge to healthcare organisations. By understanding what drives some of the 
beliefs about the older nurse, opportunity is created to challenge and seek ways to support the culture to change. This research provides an opportunity to explore from a New Zealand perspective what environment could provide support and retain the older nurse in the workforce.

The next theme of the review seeks to understand one of the drivers that exists and that may shape the beliefs held about older nurses in the workplace by exploring the concept of age discrimination and the older nurse.

\section{Age discrimination and the older nurse}

The Human Rights Act 1993 and the Employment Relations Act 2000 prohibit age discrimination in relation to employment. There is no compulsory retirement age in New Zealand and it is unlawful, (apart from some defined exceptions) to make an employee resign due to age (Department of Labour, 2009). In 2001, the New Zealand Positive Aging Strategy was launched as a structure for setting the policy direction not only for older New Zealanders, but for all generations (Ministry of Social Development, 2001). One of the goals outlined in the strategy relates to employment and the elimination of ageism in the workplace. This goal strongly encourages the development and implementation of:

human resources policies in the Government sector that support employment of older workers provide family-friendly workplaces by recognising those with caring responsibilities and allow flexible and reduced hours of work; and ensure entitlements for training are provided to all workers, including older workers. (p.98)

Dennis and Thomas (2007) define ageism as "when age biases negatively affect workplace decisions about employment, termination, retirement, benefits, and training and promotion opportunities, age discrimination is in action" (p.84). The development of a strategy does not mean that it will be implemented. The Human Rights Act 1993 aimed to prevent discrimination. Despite this legislation, Alpass and Mortimer (2007) argue age discrimination continues, and that the perception that older workers 
are set in their ways and not able to easily adapt is one that is often perpetuated by both the older worker and their peers. Societal norms value the young and fit. Dennis and Thomas (2007) suggest that commonly held myths, such as the belief that performance decreases with age, that older workers are resistant to change and are unable to keep up with technology, place unnecessary barriers in the way of older workers. Other commonly held views of the older worker include that aging induces reduction in physical and mental capability, sick leave increases and older workers lack the interpersonal skills of the younger generations e.g. teamwork, problem solving ability and initiative (Alpass \& Mortimer, 2007; Hatcher et al., 2006; Letvak, 2002b).

In relation to the older nurse, Letvak (2002a) attempts to dispel some of these commonly held perceptions, arguing that chronological age is a weak predictor of performance. The older nurse is adaptable and, as demonstrated in her research, when comparing sick leave, older and younger nurses take very similar amounts. Cofer (1998) describes misconceptions about older nurses as harmful and suggests that they can influence the behaviour of older nurses and their managers. Cofer claims "older nurses perform as well or better than younger nurses and rank highly in positive interpersonal skills" (p.34). Mion et al. (2006) outline the benefits to the organisation, patients and peers that the older nurse brings. For the organisation, benefits include historical knowledge and commitments. For the patients, benefits are the value of life and clinical experience. The older nurse can provide a mentoring and leadership role to novice nurses sharing their practice wisdom and contributing to the preparation of the next generation of nurses. Fitzgerald (2007) provides a view from the literature that older nurses demonstrate "a more deeply rooted understanding of the needs of patients, offering experience and wisdom that can only come from years of patient care" ( $p$ 238).

Andrews et al. (2005), when discussing the older nurse and age discrimination, describe the gap that exists between what is legislation and what is practice. They further assert that until organisations demonstrate awareness of the issues in relation to the older nurse, particularly age 
discrimination, and actively have policies and education in place that support the retention of the older nurse, the status quo will remain unchallenged. They conclude that we will continue to lose prematurely, valuable knowledge and wisdom from a vulnerable workforce. In relation to the research topic understanding age discrimination, as a potential barrier to older nurse retention is important as the impact of the environment the older nurses practices in is considered. Whilst the focus of this research is the older nurse he/she does not exist in isolation in the workplace. The ways in which a range of generations in the workplace relate to each other is also likely to impact on the retention of the older nurse. Indeed the generational context of a workplace is linked to tensions and challenges that may influence retention and behaviours of nurses across the generations.

\section{Generational tensions}

There are four generations currently working in the health care environment (Fitzgerald, 2007). It is suggested that a generation grouping has a set of common characteristics that gives them identity (Letvak, 2003). The details for each generational grouping vary slightly in the literature but generally fall into the following categories: Silent (Veteran) generation born 1922-1941 with approximately 24\% in the nursing workforce, Baby Boomers born 1941-1960 with approximately $47 \%$ in the nursing workforce, Generation X born 1961-1980 with approximately 21\% in the nursing workforce and Generation $Y$ born 1980-1994 with approximately $8 \%$ in the nursing workforce (Hu et al., 2004).

$\mathrm{Hu}$ et al further suggest that the four generations life experiences and expectations will affect how they respond to situations. Each generation also has a different context and the values and norms that shape their view of the world are heavily influenced by them. When discussing values and attitudes, Crumpacker and Crumpacker (2007) describe the impact of influences and experiences in the formative years as contributing factors to people's core beliefs, expectations of others and the formation of individual values. Although they will have their own individual values those 
who have shared similar "social forces" (p.352) growing up are likely to share similar values sets as well.

Crumpacker and Crumpacker (2007) suggest that each generation has "observable characteristics" and that these relate to "ethics, work-life balance, authority and leadership and technology" (p.352). The silent generation lived through times of hardship including the great depression and World War Two. Weick (2007) suggests that women of this generation were socialised to become "homemakers and raise children" (p.2) and further comments that this socialisation means that they understand and seek formality and hierarchical structure. This generation values hard work and loyalty, and as a result has high expectations of those around them to also meet the standard. This can lead to generational tension. The next generation is the baby boomer generation, growing up in the time of the civil rights movement, feminism and the Vietnam War (Crumpacker \& Crumpacker, 2007). This generation saw women entering the workplace in high numbers, increased divorce rates and the launch of the woman as a consumer. Hu et al. (2004) describe nurses of this generation as willing to work for success, loyal to an employer if the conditions are right, politically active if they are personally affected but generally avoiding conflict. They have worked hard to get where they are and feel they deserve what is due to them.

When commenting on the nurses from Generation X (children of the baby boomers), Letvak (2003) describes them as "blunt, self reliant and unwilling to take work as seriously as their older peers" (p.51). The social context of this generation was one of early independence. Coming from the parents of the baby boomer generation it is likely that half had divorced parents and working mothers. Nurses from this generation are unlikely to be as loyal as previous generations, will be focused on outcomes and not keen on process. Further, they are more technologically aware and likely to be more highly qualified (Hu et al., 2004). Wallis (2009) describes the youngest generation, Generation $Y$, as one that has grown up in times of globalisation and who live in an affluent and multicultural world that is dominated by the internet. Words used when discussing 
Generation $\mathrm{Y}$ include optimism, confidence and highly intelligent (Crumpacker \& Crumpacker, 2007; Hu et al., 2004; Wallis, 2009). Nurses from this generation have high expectations of themselves and their work environment. Weick (2007) argues that it is these high expectations that can lead to dissatisfaction. Also nurses from this generation will work hard and be flexible for the right workplace. However, if the workplace fails to meet expectations, they will quickly move to one that does. Another point of difference is that technology does not mean computers to this generation, it is the norm and what they have grown up with (Hu et al., 2004). Despite well documented generational characteristics, Crumpacker and Crumpacker (2007) suggest that there is risk associated with focusing on the perceived issues of a multigenerational workforce and the danger of stereotyping. They balance this view with the comment that workplaces need to understand the demographics, values and norms of the staff to ensure the culture works to address the needs across the generations.

Letvak (2003a), using voices of the older nurse, describes the tension that can exist when there is a range of generational values in the workplace. Older nurses view themselves as experienced and loyal, but feel undervalued and viewed as not having the skills of the younger nurses. They describe the younger nurse as being in it for the money and not prepared to do the time, expecting instant gratification. Making assumptions about different generations is not without risk, but it does highlight the importance of knowing the workforce, what motivates them, how they learn and what keeps them at work (Crumpacker \& Crumpacker, 2007). The presence of a range of generations in the workplace is a reality and how managers and organisations work to provide a culture of understanding and tolerance is a key retention factor for the older nurse (Wallis, 2009).

Understanding and tolerance in the workplace is required for generational harmony. The NCNZ scope of practice requires registered nurses to work as part of a team in an effective manner (NCNZ, 2010). Nurses in leadership positions have the ability and responsibility to oversee and manage teamwork in the clinical environment ensuring the culture of the 
workplace is one that supports all generations of nurses. In relation to the research topic generational factors, also impact on the environment the older nurse practices in and may influence retention. Another key factor in relation to retention of the older nurse is the influence of line manager behaviour (Cohen, 2006; Letvak, 2003).

\section{Line manager behaviour and retention}

Having a positive relationship with one's line manager is reported to be a key job satisfaction indicator (Hatcher et al., 2006). Buerhaus et al. (2005) support this by observing that, when registered nurses perceived positive relationships with managers, they were more satisfied and less likely to leave, describing a direct link between line manager behaviour and the retention of the older nurse. The role of the line manager is pivotal in influencing the culture and environment of the clinical setting in which the older nurse works. Anthony et al. (2005) describe the role as complex and multifaceted, with the manager acting as the bridge between senior management and the nurses at the bedside. Piktialis (2007) discusses research in relation to ideal workplaces for older workers describing an employee's decision to stay or go as being directly influenced by the dayto-day behaviour of the direct line manager. Kupperschmidt (2006) describes nurses from the silent and boomer generation as seeing nursing as a calling, a profession they joined because they wanted to make a difference. This generation of nurses pride themselves on high standards and professionalism. They are loyal and value hard work, with self worth closely aligned to this work ethic. Consequently they are likely to expect reward for their loyalty and hard work from their managers. Weick (2007) suggests that nurses from these generations like to be told how good they are, expect their managers to know them personally and are not fond of direct suggestions for improvement but are likely to respond well to one on one interaction with their manager.

Older nurses are more likely then, to respond well to line managers who have the ability to listen, value their staff, have a nurturing leadership style and "in particular older nurses prefer managers who are professional, 
demonstrate integrity and who empower their workers" (Hu et al, 2004, p.339). Managers are the filter through which legislative and organisational policy and process are passed through to the nurses at the bedside. Their job requires them to have the skills to manage and lead the staff to provide safe patient care within these frameworks. The manager sets the tone for the environment and, as Anthony et al. (2005) outline, must balance the competing demands of creating a positive environment to retain staff and the reality of the day-to-day running of a busy clinical environment set against a backdrop of "institution or system needs" (p.2). Layered into this complexity are the future health workforce issues, retention of all staff and management of a multigenerational workforce.

When considering the needs of the older nursing workforce, providing an environment that is conducive to retaining this cohort of nurses for as long as possible is crucial. Research to date suggests that, although legislation and strategies are in place to prevent age discrimination and to support older workers, very few health care organisations have implemented policies to achieve such standards (Andrews et al., 2005; Fitzgerald, 2007; Letvak, 2002a; McHaney \& Varner, 2006; Watson et al., 2003). This is arguably where the skill and leadership of the line manager is crucial. Anecdotal evidence suggests, however, that informal strategies do occur in relation to retention of the older nurse and the true skill of a successful manager is the way in which they balance this with the needs of the wider team. Letvak (2002b) believes that it is imperative that managers have the skills to manage older workers and suggests that as a first step, the manager must reflect on their own views and beliefs about ageism, then work to make ageism unacceptable in their own workplace. Having an awareness of the characteristics of each generation in the workplace and what they expect from their leader is advocated by Hu et al. (2004). Role modelling, tolerance and understanding, and working from a position of shared values are also put forward as strategies that could be utilised by line managers. From an organisational perspective consideration of the appropriate support and preparation for line managers or as Anthony et al. (2005) describe them, 'Chief Retention Officers' (p.3) would seem an 
effective strategy to address older nurse retention. Norman et al. (2005) suggest that nursing leadership and management, undergraduate and postgraduate education should emphasise how graduates can effectively work with and aging workforce. At an organisational level Letvak (2002a) encourages organisations to provide training to address ageism and to encourage "fair and equitable treatment for all workers" (p.1106). The literature supports the selection of the CNM group for the purpose of this research. This group has an influential role in the retention of older nurses and a further understanding of how they influence retention in a New Zealand context is an important aspect of this research.

\section{Summary}

The literature reveals the challenges ahead for the future health workforce, the older nurse, the culture of the health care environment and factors influencing the retention of the older nurse. As a short to medium term strategy, the experience, practice wisdom and loyalty of the older nurse may lend stability in a rapidly changing health care landscape. Societal views of aging and discrimination impact on the choices older nurses make about staying in the workplace. Older nurses view their world with their own generational context where loyalty, work ethic and respect are important. The relationship they have with their direct manager is a key factor that influences their decision to stay in the workplace. How this international literature relates to the New Zealand environment is largely unknown. Although several authors offer suggestions and strategies to improve retention and job satisfaction among older nurses, the literature reviewed also supports the notion that the leadership ability of the manager is key to retaining this cohort of nurses. If healthcare organisations in New Zealand wish to support retention and support for older nurses, it is important to establish current levels of understanding amongst line managers concerning the older nurse in the workplace. From this perspective, both informal existing support and retention strategies and international recommendations can be evaluated in the New Zealand context. The following chapter outlines the methodology utilised in the exploration of these in two DHB settings in New Zealand. 


\section{Chapter Three: Methodology}

\section{Introduction}

This chapter explains and provides a justification for the methodological approach, method and design selected to answer the research question: Are Clinical/Charge Nurse Managers aware of the issues facing older nurses in the workplace and do they utilise strategies aimed at retaining older nurses? This description will also include the approach to the sample selection, how the data collection tool was adapted, steps taken to ensure validity and reliability, ethical and cultural considerations and finally data collection methods and data analysis.

\section{Methodology}

An exploratory descriptive survey design was selected to answer the research question. The literature suggests that a survey design is a valuable research tool for seeking to understand knowledge, attitudes and behaviours of populations. It is further suggested that surveys are a way to gather and analyse information in a comprehensive way to guide decision making (Leaver, 2000; Rubenfield, 2004). Surveys can use a quantitative approach, and as Wagstaff (2000) describes, descriptive surveys can be used to identify relationships between variables. However, as with the tool used for this research, qualitative analysis of the "free text" responses is an acceptable method of enriching quantitative findings (Leaver, 2000). Coughlan, Cronin, and Ryan (2009) comment that descriptive surveys provide a "snapshot of the phenomena being studied" (p.9). From a researcher's perspective using a descriptive survey design is relatively straightforward and on most occasions data can be gathered from a single contact. Veale (1998) describes surveys as being able to provide information to test hypotheses, measure and determine the extent and nature of a phenomenon, and importantly in relation to my enquiry, surveys can be used to generalise findings to other similar groups or populations. In the context of this study, the exploratory questionnaire is used to link existing knowledge (from the literature) with survey participant responses to highlight areas of relevance for the New Zealand context. 
Surveys are able to access a large sample at reasonable cost. They can, if well designed and aligned to the research objectives, be used successfully to gain insight into attitudes, beliefs and behaviours, used across a wide range of populations and repeated at a reasonable cost. Wagstaff (2000) states that "surveys can generate knowledge about something in order to improve it" (p.60). Wagstaff further recommends that prior to selecting a survey method, several simple but essential conditions should be considered as they will contribute to the overall value of the survey. These include ensuring that "the target population is clearly defined, the target population is easily identified and the majority of respondents will be able to answer the questions" (p.64). In relation to this study, the population to be surveyed was able to be clearly defined and identified, using existing workforce data and role descriptors. From my knowledge and experience of the role and context in which the CNM practices, I was able to predict with some confidence that the topic would have relevance to the group and that the majority of study participants would be able to complete the questionnaire. As I sought to gain insight into beliefs and behaviours of the CNM group in relation to the retention of the older nurse, a survey was selected as most appropriate choice for the purpose of this research. Leaver (2000) describes two general types of surveys: a census or status survey and a sample survey. A census or status survey is about questioning the whole population, whereas a sample survey involves a researcher selecting a sample from the population and then attempting to generalise findings.

Some disadvantages of surveys include potential issues around low return rates, and the motivation and ability of respondents to reply truthfully and accurately. A poorly designed questionnaire can mean that respondents are either unable to answer the questions or they may find them intrusive or irrelevant (Veale, 1998; Wagstaff, 2000). Most survey questionnaires provide a cross-sectional view of the area of interest, and they may not capture complex real life issues adequately. The researcher is not there to provide explanation of the question nor ask for further clarification. A researcher selecting this method needs to ensure that the questionnaire is 
well designed and pilot tested to reduce these potentially confounding factors (Veale, 1998; Wagstaff, 2000). Pretesting was undertaken following adaptation of the survey for this research.

\section{Method}

\section{Research question}

Coughlan et al. (2009) state that the first stage of any successful survey research is "the identification of an explicit research problem" (p.10), cautioning the researcher to be precise with the questions being asked, ensuring they relate directly to the research question being asked. There is a risk of asking too many or vague questions in a survey. This may mean the researcher will reach the end and discover the findings have little meaning to the original research question. Halburg (2008) suggests following the development of the research question, the researcher should consider what they expect to find with the research, and what if any variables might need to be adjusted when formulating the questions. Halburg further suggests using the literature as a first step (as cited in Coughlan et al, 2009). This is not to pre-empt the outcome of the research, but to contribute to the validity and reliability of the findings, ensuring they have meaning in relation to the research question.

The beginning point for this research came with my questioning, what Clinical/Charge Nurses Managers (CNM) do (if anything) to retain older nurses. This led to the formulation of a specific research question: Are Clinical/Charge Nurse Managers aware of the issues facing older nurses in the workplace and do they utilise strategies aimed at retaining older nurses? Considering what the findings may be from this research question was also important at the beginning. Observation and experience had contributed to some general assumptions of the group that would be completing the survey, so it was important that the survey questions selected captured the topic as intended. Undertaking an extensive review of the literature in relation to the research topic helped refine the research question and adaptation of the questionnaire. The literature review also supported the choice to undertake this research using a survey. This 
method was a common tool used to gather data in relation to the older nurses in the international literature.

\section{Sampling}

As a sample survey is used for the purpose of this research, sampling bias had to be taken into consideration. Rubenfeld (2004) describes sampling bias as occurring when the results of the survey deviate from the truth because the sample selected by the researcher was different from the population that the researcher intended to describe. It is a reasonable step to select a predetermined sample, sometimes referred to as a convenience sample (Wagstaff, 2000). Steps I took to reduce sampling bias included gaining an understanding of the population I wanted to survey. The position title and role descriptor of the CNM role, in a DHB setting was scoped and endorsed at a national level in New Zealand in 2007 following the 2006 Nursing and Midwifery Multi Employee Collective Agreement (MECA). The exact number of CNMs in New Zealand is not easily attainable, as there is limited information available outside the DHB setting.

NCNZ (2010) report that there are currently 42,662 registered nurses holding a current practising certificate in New Zealand. District Health Boards of New Zealand (DHBNZ) is currently undertaking a range of Future Workforce initiatives, one of which is the development of the Health Workforce Information Programme (HWIP). This aims to provide regular information and analysis of the health workforce. It has started this process with the $21 \mathrm{DHBs}$ as the data are more readily available. Their June 2008 database report shows that just under half of nurses with a current practising certificate ( 20,308 ) work for a DHB. They have further broken that down into areas of practice, including one area of practice defined as the Nurse Manager. They have used this as an inclusive title to include all nursing leadership positions including Director of Nursing, Nurse Manager and Clinical/ Charge Nurse Manager. This group has 692 members. I decided to select two groups of CNMs from similar size DHB hospitals in two separate geographical locations. Although a small study, 
using two separate DHBs contributed to reducing sampling bias. A sample size of $90 \mathrm{CNMs}$ would therefore give me a snapshot of approximately $15 \%$ of the DHB CNM group. As the role descriptors for the CNM role are similar and have been scoped at a national level I believe this sample size will mean that the findings will be able to be generalised to the wider CNM group.

\section{The questionnaire}

The questionnaire (Appendix A) was adapted from an earlier survey questionnaire undertaken by Letvak (2002a). Permission to use and/or adapt the survey questionnaire was granted by Letvak via email correspondence (Appendix B). Using or adapting a questionnaire is an acceptable approach for any researcher (Coughlan et al., 2009). The design of a new questionnaire is a complex and time consuming process, although as Wagstaff (2000) cautions using a pre-existing questionnaire does not mean you should assume validity and reliability, particularly if it has been used in another country or subject group. The original survey by Letvak has been successfully replicated by other researchers in the North American healthcare setting, producing similar results (McHaney \& Varner, 2006). The literature review and existing knowledge of the New Zealand healthcare context provided some confidence in relation to the suitability of the use of the survey to answer the research question. I decided to adapt the existing survey. The key change was to describe strategies identified from the literature so participants could respond to specific strategies and comment on their usefulness. Illustration of the adaptations is shown in Table 1. 
Table 1: Comparison of adapted survey

\begin{tabular}{|c|c|}
\hline Letvak survey summary (2002) & Adapted survey summary \\
\hline $\begin{array}{l}\text { Sample: Hospital nursing administrators } \\
\text { (160 hospitals, } 411 \text { nursing homes) in } \\
\text { North America }\end{array}$ & $\begin{array}{l}\text { Sample: Two groups CNMs (CNM) in two } \\
\text { large tertiary hospitals in New Zealand }\end{array}$ \\
\hline $\begin{array}{l}\text { Demographic data sought: } \\
\text { Type of facility } \\
\text { Number of beds, } \\
\text { Number of RN staff }\end{array}$ & $\begin{array}{l}\text { Demographic data sought: } \\
\text { How long in the CNM role? } \\
\text { What is your own age? }\end{array}$ \\
\hline $\begin{array}{l}\text { What percentage of employed RN's are } \\
\text { over } 55 \text { years? }\end{array}$ & $\begin{array}{l}\text { What percentage of nurses do you } \\
\text { estimate in your ward/clinical area to be } \\
\text { aged } 50 \text { years and over? }\end{array}$ \\
\hline $\begin{array}{l}\text { How aware are you about the aging RN } \\
\text { workforce? }\end{array}$ & $\begin{array}{l}\text { How aware are you of the needs of the } \\
\text { older nurses in the workplace? }\end{array}$ \\
\hline Do you wish to retain older nurses? & $\begin{array}{l}\text { Respondents using } 4 \text { point Likert scale to } \\
\text { respond to the following statement: If we } \\
\text { don't address the issues facing older } \\
\text { nurses this will have a major impact on } \\
\text { our nursing workforce }\end{array}$ \\
\hline $\begin{array}{l}\text { Is there any specific policies in place to } \\
\text { address the aging nursing workforce (or } \\
\text { any planned) }\end{array}$ & $\begin{array}{l}\text { Are you aware of any specific policies } \\
\text { within your organisation to address the } \\
\text { needs of an older nursing work force? }\end{array}$ \\
\hline $\begin{array}{l}\text { Who is responsible for assisting aging } \\
\text { nurses in continuing their employment? } \\
\text { Employers } \\
\text { Individual nurses } \\
\text { Government } \\
\text { Nursing education }\end{array}$ & $\begin{array}{l}\text { Who is responsible for assisting older } \\
\text { nurses to stay in the workforce? } \\
\text { Nurse themselves } \\
\text { CNM } \\
\text { Employer } \\
\text { Government }\end{array}$ \\
\hline $\begin{array}{l}\text { Open ended question: what specific } \\
\text { policies do you have in place }\end{array}$ & $\begin{array}{l}\text { Below are some strategies that have } \\
\text { been suggested to address the needs of } \\
\text { an older nursing workforce: Please } \\
\text { indicate your opinion on the usefulness of } \\
\text { each strategy } \\
\text { Increased flexibility with rostering } \\
\text { Improved lifting and handling } \\
\text { devices } \\
\text { Consideration of the environment } \\
\text { including flow of the ward and } \\
\text { lighting } \\
\text { Part time hours and flexible shifts } \\
\text { Start superannuation after the age of } \\
60 \text { to supplement part time work } \\
\text { Older nurses utilised to orientate } \\
\text { younger nurses } \\
\text { Increased professional development } \\
\text { opportunities }\end{array}$ \\
\hline \multirow[t]{3}{*}{$\begin{array}{l}\text { Open ended question: Any further } \\
\text { comment on the issue? }\end{array}$} & $\begin{array}{l}\text { Open ended question: What strengths do } \\
\text { older nurses bring to the nursing } \\
\text { workforce? }\end{array}$ \\
\hline & $\begin{array}{l}\text { Open ended question: Are there any } \\
\text { further strategies you use to address } \\
\text { issues facing older nurses in your clinical } \\
\text { area? }\end{array}$ \\
\hline & Any further comments? \\
\hline
\end{tabular}




\section{Adaptation of the survey}

In relation to question one and two, the type of facility being surveyed was known and I wanted to know more detail about the CNMs themselves, particularly in relation to the length of time in the role and own age. This provided a background to the group being surveyed. Question three was adapted to reflect the majority of the literature reviewed where an older nurse was described as aged 50 and older. Questions four to seven were adapted to ensure consistent use of the term older nurse and to reflect familiar terminology. Question eight as discussed, was structured, so participants could respond to specific strategies and comment on their usefulness. Question nine and ten were added to provide opportunity for qualitative data to be gathered.

\section{Validity and reliability}

A survey was selected as the most appropriate method for this research providing a snapshot of the attitudes, beliefs and behaviours of the CNM group in relation to the research enquiry. However, it could be argued that one can never be truly objective when undertaking survey research, as the researcher has an obvious interest and knowledge of the topic selected, and the sample you choose to survey will have different motivations and reasons for completing the survey (Boynton, 2004). The challenge to the researcher is to ensure to the best of their ability that the research being undertaken has validity and is reliable. Any research needs to show validity by asking what it means to ask and be reliable by being clear about who is being sampled and consider the extent to which it represents the wider population (Wagstaff, 2000). Demonstrating reliability when using survey method requires consideration of the sampling and response rates, the quality of the questionnaire, clear analytical process and discussion around the generalisability of findings (Veale, 1998). Due to the limitations in the scope of research possible for this thesis, the sample was restricted to one professional group (CNMs) in two similar sized healthcare settings (two tertiary hospitals). Two strategies were adopted in this study to increase the ability to generalise findings and increase reliability. Firstly a pre-existing questionnaire that has been used 
successfully in a range of health care settings was selected (with some adaptations). Secondly, the role of the CNM in a DHB setting has been nationally scoped and has similar role definition across the 21 DHBs, including line management responsibility for older nurses. The sample size represented approximately 15\% of the CNMs working in DHBs in New Zealand giving a level of confidence that the findings could be generalised to the wider CNM group.

To maximise the response rate and participation I ensured that the questionnaire was pre-tested for the New Zealand setting. Wagstaff (2000) suggests that questions to be asked when pre-testing a questionnaire should include, "Were the instructions clear? How long did it take to complete? Were any of the questions ambiguous? Did you object to any of the questions? Do you think any questions have been omitted?" (p.67). I pre-tested the adapted questionnaire with three CNMs in a different DHB. Feedback received was favourable. All three respondents commented that it was easy to complete and the questions were clear. The questionnaire responses received provided the kind and range of information I was seeking, therefore no changes to the questionnaire were made following the pre-test.

Wagstaff (2000) suggests that validity and reliability of the findings are also highly dependent on response rate, describing postal surveys as generally having a smaller response rate $(30-40 \%)$. To further maximise participation and response rate, it is suggested that a questionnaire must be well presented, free of spelling errors, not contain long questions, and care must be taken with wording and layout of questions to ensure they are not worded negatively, double-barrelled, biased or leading (Veale, 1998; Wagstaff, 2000). Care must also be taken in ensuring that the language and terminology is appropriate to the group being surveyed. This was taken into consideration when adapting the survey and pre-testing provided a level of confidence that the language and terminology was appropriate. 
The response rate can be further enhanced by ensuring that the purpose and the value of their participation are clear to the participant. Measures were taken to ensure that the covering letter (Appendix $\mathrm{C}$ ) outlined the purpose of the research, by clearly stating who was supporting it, that it had ethical approval, and that clear instructions on how to complete the questionnaire were provided and return instructions clearly outlined. Information concerning management of the data and assurance of anonyminity was also provided (Boynton, 2004; Statistics New Zealand, 1995; Veale, 1998).

Rigour of the findings can also be enhanced by ensuring that the attention is given to accurate entering, checking and cleaning of the data once collected, that there is comment on the response rate and that appropriate statistics are used in the report of the findings (Boynton, 2004; Statistics New Zealand, 1995). Three open ended questions were included in the questionnaire providing qualitative data. When considering the validity and reliability of the qualitative data Graneheim and Lundman (2003) suggest validity and reliability of qualitative data is demonstrated by "trustworthiness" (p.108) that is the researcher must demonstrate credibility in determining the focus of the study, the method and amount of data collected. Credibility is also achieved when the researcher can demonstrate how the data were utilised and that the themes presented are supported with representative quotations from the participants. Further contributing to trustworthiness is the degree to which the findings can be transferred to other settings or groups. Graneheim and Lundman comment that the researcher can give suggestions relating to the transferability of the findings but it is the consumer of the research that will make the decision as to that application of the findings to another context. Strategies to demonstrate transferability include ensuring the context and participants of the study are clear to the reader and that the findings are clearly presented and supported appropriately from the data. Trustworthiness usually relates to the interpretive research approach, in the context of this research, the important elements of trustworthiness are used in relation to the open ended questions in the survey. 


\section{Treaty of Waitangi considerations}

In New Zealand, health research that may involve Māori is guided by the principles embedded in the Treaty of Waitangi as the founding document of New Zealand. "The principles of partnership and sharing implicit in the Treaty should be respected by all researchers and where applicable incorporated into all health research proposals" (Health Research Council, $2008, p .4)$. This study has not been designed specifically to include or exclude participants based on their ethnicity. Guidelines from the Health Research Council were used to consider whether specific consultation was required. This is recommended if Māori are to be involved as participants or the project relates to a health issue of importance to Māori. Specific ethnicity data were not requested.

\section{Ethical considerations}

Beanland et al. (1999) suggest the basic ethical principles relevant to the conduct of research must include "Respect for the persons, Beneficence, and Justice" (p.151). Respect relates to all humans having the right to selfdetermination. In relation to this research participants were free to complete the questionnaire or not. Care was taken in presenting the questionnaire and ensuring the accompanying information clearly explained the purpose of the research. Beneficence uses the principle of do no harm, that is people are treated ethically and their decisions are treated respectfully. Justice requires all people to be treated fairly and that the research does not place undue burden on them. These basic principles formed the framework for ethical considerations, consent was assumed by completion and return of the survey. Polit, Beck and Hungler (2001) comment that obtaining written consent when using a selfadministered questionnaire is usually not required, the return of the questionnaire assumes implied consent. Anonymity was maintained as participants were not identifiable.

Consideration of the design of the study was also an important part of the research planning. Wagstaff (2000) asserts that a poorly designed study may have the potential to be unethical as it potentially wastes participants' 
time, and may not contribute to increasing the body of knowledge of the topic. This research focused on one particular age group and feedback received on the proposed topic had suggested some sensitivity around the wording 'older nurse', along with the awareness that a proportion of the CNM group being surveyed would be in that age group. A clear rationale for the research was therefore essential. Steps taken to address this included ensuring the covering letter clearly outlined the purpose of the research to participants and that a clear rationale of the use of the term older nurse was provided. There was a potential conflict of interest as one of the survey areas was my own practice area at the time. In order to reduce this potential conflict there were no identifiable features of the areas used in any aspect of the research. This was also raised by the Victoria University of Wellington Human Ethics Committee which prior to approving the ethics proposal, required confirmation that I had no direct line management relationship with the participants. Following this confirmation, ethics approval was granted (Appendix D).

\section{Data collection}

Permission was sought from the Directors of Nursing at both DHBs to undertake the research. Both Directors of Nursing were very supportive of the research offering to assist with distribution of the questionnaires. The exact number of CNMs in each hospital was confirmed to ensure that each Director of Nursing's personal assistant was provided with the correct number of surveys, covering letters and postage paid return self addressed sealable envelopes. These were sent to the CNM groups through the hospital's internal mail system. The self-addressed envelope was addressed back to the personal assistants who collected the sealed surveys and returned them to me at the completion of the survey. Midpoint during the survey period each personal assistant was contacted to ascertain the return rates. Both indicated a very favourable return rate therefore follow-up with the participants was not undertaken. The surveys were distributed during the first week in July 2008, with a closing date of 1 August 2008. 


\section{Data analysis}

Descriptive statistical analysis was used as the method for organising, summarising and presenting the numerical data (Botti \& Endacott, 2006). Descriptive statistics provide a way of summarising data in a way that is meaningful to both the researcher and the reader (Brillhart, 2007). Botti and Endacott, when discussing data analysis describe four levels at which data can be measured: nominal, ordinal, interval and ratio. The questionnaire elicited nominal and ordinal data in addition to qualitative data. Nominal scales are often used to gather information on such things as the demographics of study participants (Crichton, 2001). The questionnaire asked four questions using nominal scales. When reporting nominal data usually the frequency of each category is counted and the percentage of the total of each category is presented in graph or table form (Botti \& Endacott, 2006). Ordinal scales measures in a way that describes rankings of events or objects. Botti and Endacott describe ordinal data as being able to provide more information than nominal level data as the researcher is able to demonstrate the ranking of a particular characteristic. A common example of ordinal scales is the Likert scale. Three questions were asked using the ordinal Likert scale. Wagstaff (2000) outlines that Likert scales provide a way of asking closed questions with fixed term responses, which may simplify the process for the person completing the questionnaire and assist with the analysis, but in doing so may limit the information gathered on the topic. Wagstaff further discusses that the wording is important with attention required to the amount and structure of positively and negatively worded phases to reduce bias. Ordinal data collected are presented as medians and percentages in this report.

Analysis of the qualitative data collected from the three open ended questions was completed manually. Roberts and Taylor (1998) describe this as an acceptable approach to analysing qualitative data. Using a thematic content analysis approach all responses from the open ended questionnaires were handwritten under each question heading (Burnard, 2003). The responses from Questions seven, eight and ten were read and 
reread, the responses were coded and grouped into themes from most prevalent to least prevalent (Steinhauser \& Barroso, 2009). The approach to analysis was exploratory. As Steinhauser and Barroso describe when discussing exploratory qualitative analysis, the researcher conducts a "thematic survey" (p.728) eliciting broad themes, that can be illustrated with quotes from participant responses, contrasting this with a more explanatory approach where the researcher conducts a more in depth analysis and moves to the development of a theory. For the purpose of this research the exploratory approach provided a method of grouping the participant responses into themes that enriched the descriptive findings.

Each returned survey was checked for question completion, numbered and coded for DHB. A code book was commenced before any analysis took place. Wagstaff (2000) describes coding as giving a number to each answer of the questions you asked, with closed questions such as demographic data or questions requiring yes/no or agree/disagree responses being easier to code. For example participants were asked 'Are you aware of any specific policies within your organisation to address the needs of an older nursing work force?' The answer choices were yes or no, the codebook recorded yes $=1$ no $=2$. The Statistical Package for Social Sciences (SPSS Version 16.0) was used to enter and analyse the quantitative data. Wagstaff (2000) \& Boynton (2004) recommend the use of an electronic database such as SPSS to assist with the collation and analysis of the data collected.

\section{Summary}

The intent of the data analysis in this report is to provide descriptive analysis of the nominal and ordinal data and to analyse the qualitative data gathered from the open-ended questions into themes. Some aspects of the adapted questionnaire did prove to be problematic when analysis was undertaken. These will be addressed in Chapter Six. The scope of this study was to provide a snapshot of two groups of CNM in relation to retention of older nurses and the method of data collection provides an opportunity to summarise patterns of response from this CNM sample. Chapter Four will present the findings from the data collected. 


\section{Chapter Four: Findings}

\section{Introduction}

This study sought to explore the awareness of two groups of CNMs from two similar size district health boards in New Zealand regarding the issues facing the older nurse in the workplace, and to establish their views on suggested strategies identified in the literature to address the issues. The survey also asked respondents to outline any further strategies they utilised to support older nurses in the workplace. Further, respondents were asked to comment on what strengths older nurses bring to the workplace, what their view was on who is responsible for their retention and the impact on the nursing workforce of not retaining older nurses.

\section{Response rate}

In total 90 questionnaires ( $\mathrm{n}=45$ per hospital) were sent to two Directors of Nursing in two similar sized hospitals within two separate district health boards. The personal assistants of the Directors of Nursing mailed them internally to the CNMs. Provided with each questionnaire was a selfaddressed envelope to return the completed questionnaires to the personal assistants, who then assembled the responses and returned them unopened to the researcher. A requested four week response time was indicated on the questionnaire with the intention of a reminder email at the two week point. This reminder email was not required as the response rate within the set time period was high. A total of 76 questionnaires were returned (DHB one $n=35$ ) and (DHB two $n=41$ ), representing a response rate of $84.5 \%$. The standard of completion was high with very few incomplete responses. No questionnaires were excluded from the data analysis.

\section{Demographic data}

Demographic data were collected concerning length of time each CNM had been in the role and the respondents' own age range. Length of time in the CNM role varied (see Figure 1). Of the respondents $33 \%(n=27)$ had less than five years' experience, the largest group at $42 \%(n=34)$ had between five and ten years' experience, $12 \%(n=10)$ had 10 to 15 years' 
experience and $5 \%(n=4)$ had 15 to 20 years' experience. One respondent had been in a CNM role for over 20 years'. Two thirds of the respondents had therefore had significant experience (over 5 years) in the role of CNM. Data are represented below in Figure 1.

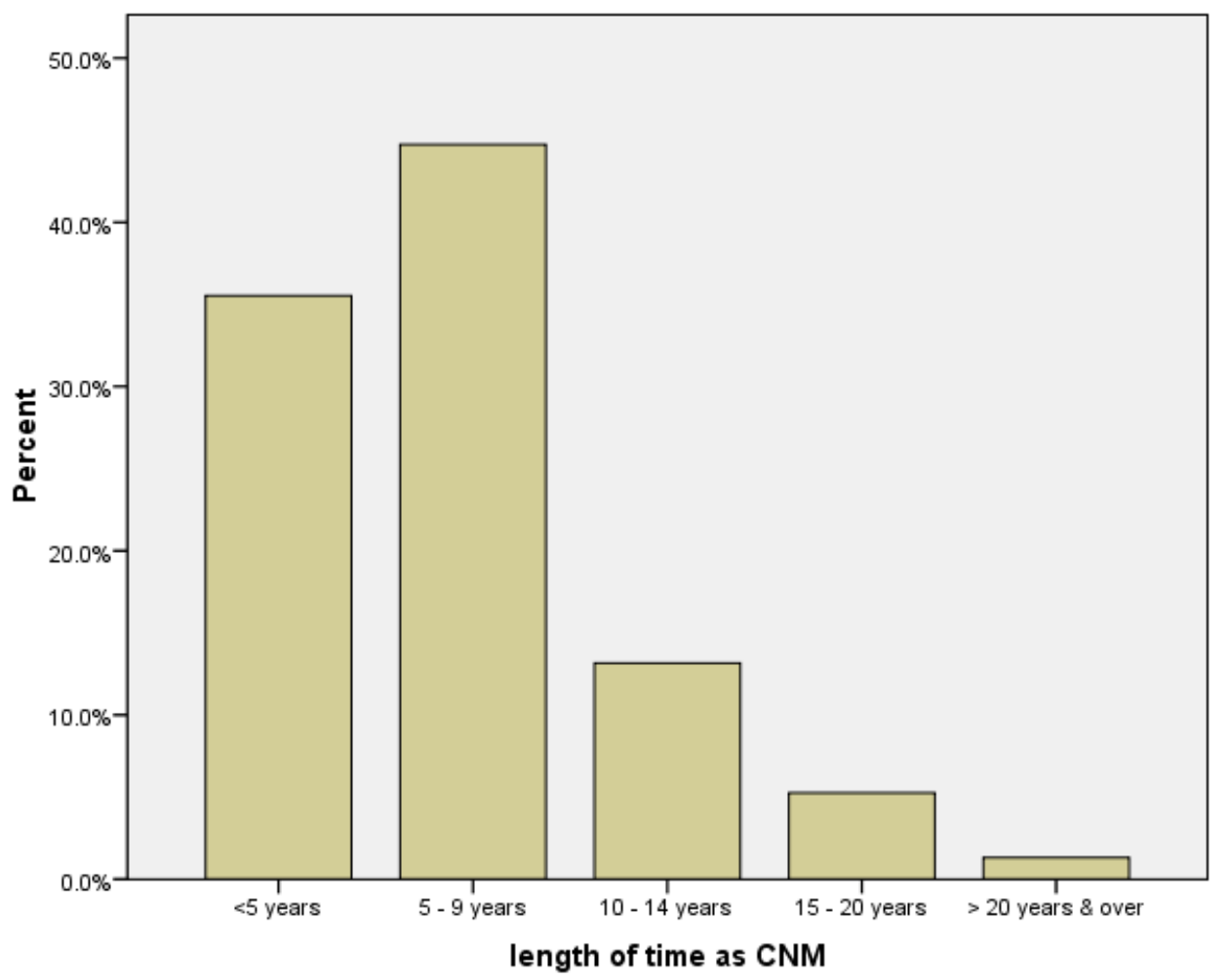

Figure 1: Length of time in CNM role

Fifty percent of the nursing workforce is aged over 47 years (HWIP, 2009). This figure was closely reflected in the respondents' own age as $43 \%$ were aged over 50 years. The age ranges of respondents are represented in Figure 2. 


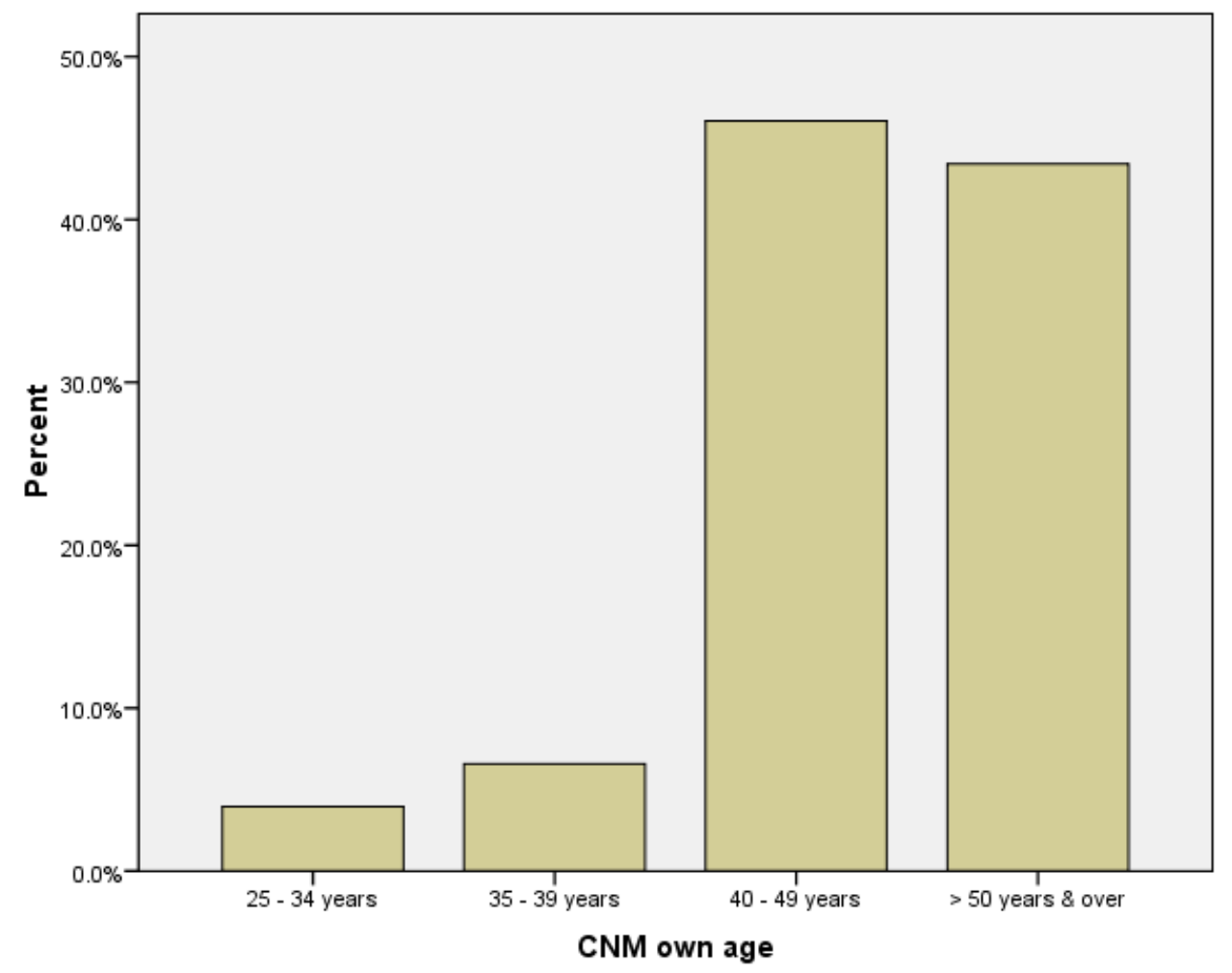

Figure 2: CNM own age

\section{Nurses aged over 50 years}

Respondents were asked to estimate the percentage of nurses aged over 50 years in their wards/clinical areas. As described in the methodology, this question was included to provide a snapshot of the age range of interest. There was a wide range of percentages reported, with only 2 respondents identifying that they had no nurses aged over 50 years working in their wards/clinical areas (Table 2).

Table 2: Estimated \% of total staff aged 50 and over

\begin{tabular}{|l|c|}
\hline $\begin{array}{l}\text { Respondents estimated \% of staff } \\
\text { aged over } 50 \text { years }\end{array}$ & Number of respondents \\
\hline $0-24 \%$ & $\mathrm{~N}=27$ \\
\hline $25-49 \%$ & $\mathrm{~N}=32$ \\
\hline $50-80 \%$ & $\mathrm{~N}=17$ \\
\hline & Total: 76 \\
\hline
\end{tabular}




\section{Awareness of the needs of the older nurse in the workplace}

Respondents' awareness of older nurses' needs in the workplace was sought using a three point Likert scale. Eighty eight percent $(n=67)$ of respondents described themselves as being very or having some awareness of the needs of older nurses. Results are outlined below in Table 3.

Table 3: Awareness of needs of older nurses

\begin{tabular}{|l|c|c|}
\hline $\begin{array}{l}\text { Respondents awareness of the needs of older } \\
\text { nurses }\end{array}$ & $\%$ & (n) \\
\hline Very aware & 57.9 & 44 \\
\hline Some awareness & 30.3 & 23 \\
\hline Somewhat aware & 11.8 & 9 \\
\hline Total & 100.0 & 76 \\
\hline
\end{tabular}

\section{Organisational policy}

Question Three asked whether respondents were aware of any specific organisational policy that existed to address the needs of an older nursing workforce. Of respondents, 92\% $(n=70)$ indicated that they were not aware of any organisational policy specifically to address the needs of the older nurse.

\section{Responsibility to retain the older nurse}

Question Four asked respondents to identify individuals and/or groups with whom responsibility lay in regards to retaining the older nurse in the workforce. Four options were given and more than one answer was able to be selected. This question received a wide range of responses. As one might expect in a complex health environment the responsibility was seen as a shared one, in which the nurse and the CNM featured in nearly all responses. Responses identified have been grouped and presented below in Table 4. 
Table 4: Responsibility for retaining the older nurse

\begin{tabular}{|l|c|c|}
\hline Person responsible for retention & \% of CNMs & $(\boldsymbol{n})$ of CNMs \\
\hline The CNM & 1.3 & 1 \\
\hline The nurse themselves & 2.6 & 2 \\
\hline The nurse and the government & 2.6 & 2 \\
\hline The employer & 3.9 & 3 \\
\hline The CNM, employer \& government & 3.9 & 3 \\
\hline The nurse and employer & 7.9 & 6 \\
\hline The nurse and the CNM & 10.5 & 8 \\
\hline The nurse, CNM and employer & 23.7 & 18 \\
\hline $\begin{array}{l}\text { All of the above (The nurse, CNM, } \\
\text { employer and government) }\end{array}$ & 43.4 & 33 \\
\hline \begin{tabular}{l} 
Total \\
\hline
\end{tabular} & 100.0 & 76 \\
\hline
\end{tabular}

\section{Strategies to retain older nurses}

The next section in the questionnaire presented a range of suggested strategies to retain the older nurse. A five point Likert scale was used to gather opinion as to the usefulness of the outlined strategies. Rostering and environmental strategies were more strongly favoured by respondents. Categories merged for data representation outlined in Table 5. 
Table 5: Strategies to retain the older nurse

\begin{tabular}{|l|c|c|c|}
\hline \multicolumn{1}{|c|}{$\begin{array}{c}\text { Suggested } \\
\text { strategies }\end{array}$} & $\begin{array}{c}\text { Percentage } \\
\text { strongly } \\
\text { agree/agree }\end{array}$ & $\begin{array}{c}\text { Percentage } \\
\text { undecided }\end{array}$ & $\begin{array}{c}\text { Percentage } \\
\text { disagree/strongly } \\
\text { disagree }\end{array}$ \\
\hline Flexibility with rostering & 90.6 & 6.8 & 2.7 \\
\hline $\begin{array}{l}\text { Improved manual } \\
\text { handling devices }\end{array}$ & 98.6 & 1.3 & 4 \\
\hline $\begin{array}{l}\text { Consideration of work } \\
\text { environment (including } \\
\text { flow of ward and lighting) }\end{array}$ & 82.7 & 13.3 & 0 \\
\hline $\begin{array}{l}\text { Part time hours and } \\
\text { flexible shifts }\end{array}$ & 97.3 & 2.7 & 7.9 \\
\hline $\begin{array}{l}\text { Start superannuation } \\
\text { early to supplement } \\
\text { income }\end{array}$ & 59.2 & 32.9 & 8 \\
\hline $\begin{array}{l}\text { Older nurses utilised to } \\
\text { orientate younger nurses }\end{array}$ & 61.3 & & 30.7 \\
\hline $\begin{array}{l}\text { Increased professional } \\
\text { development } \\
\text { opportunities }\end{array}$ & 68 & 21.3 & 10.7 \\
\hline
\end{tabular}

\section{Impact of not retaining older nurses in the workforce}

Question Six asked respondents to consider the statement: "If we don't address the issues facing older nurses this will have a major impact on the nursing workforce" Eighty nine percent $(\mathrm{n}=68)$ of respondents strongly agreed or agreed that not addressing the issues facing older nurses will have a major impact on the nursing. Results are illustrated in Table 6.

Table 6: If we don't address the issues facing older nurses this will have a major impact on the nursing workforce

\begin{tabular}{|l|l|l|}
\hline Impact on the nursing workforce & $\%$ & (n) \\
\hline Strongly agree & 56 & 43 \\
\hline Agree & 33 & 25 \\
\hline Undecided & 7 & 5 \\
\hline Disagree & 4 & 3 \\
\hline Strongly disagree & 0 & 0 \\
\hline Total & 100.0 & 76 \\
\hline
\end{tabular}




\section{Strengths of the older nurse}

Question seven used an open ended question to ask respondents to comment on the strengths older nurses bring to the workforce. All respondents answered this question. The majority using one to two words to describe the strengths as they saw them of older nurses, some offered fuller responses. Analysis of data was completed manually. Using a thematic content analysis approach all responses were grouped under the question heading. The responses were then read and reread, coded and grouped into themes from most prevalent to least prevalent. The responses present a picture of the value older nurses bring to the workforce. The most prevalent themes that emerged from this question were: experience, knowledge, work ethic, stability and relationships.

Experience: This word was used to repeatedly describe both life and clinical experience. For example one respondent commented that "nursing and life experience leads to maturity when dealing with difficult situations, they have seen it before", and another respondent commented that older nurses have "life experience - able to see the big picture".

Knowledge: Again this was a very prevalent word used by respondents. Knowledge was linked to expertise and wisdom. Nurses' broad range of knowledge, particularly organisational knowledge, was valued by the CNMs with one participant responding "they know how the systems work and utilise their contacts to know where to get help from".

Work ethic: A quarter of respondents commented on the strong work ethic that older nurses have, with some respondents relating this to older nurses not having young children at home. The comments around work ethic were related by respondents to reliability and loyalty, attributing this to generational influences. Loyalty to the organisation was commented on, with one participant stating that "they are loyal to the organisation and colleagues so turn up to work". Another commented that older nurses have an "excellent work ethic". 
Stability: Older nurses bring stability to the team, this was commented on by a number of respondents. Some related this to maturity, and described the balance that older nurses bring to the clinical environment. The stability of the older nurse was again linked to the perception of having fewer pressures outside work with one respondent commented that older nurses have "more stability - i.e. less family disruptions e.g. parental leave and have usually completed OE/travel".

Relationships: The value of older nurse's relationships within the team was woven throughout the responses. This included comments on their relationships with the patients and their families, the wider health care team and their colleagues. Several respondents commented on the ability of older nurses to act as role models and mentor younger nurses and their ability to support the CNMs with leadership in the clinical environment. "I value that some older nurses remain passionate about nursing and want to share that with the younger/new workforce".

Seven of the participants balanced their comments on the strengths of older nurses with additional commentary. One participant when discussing the value of life experience cautioned that this can be an asset but also can lead to resistance to change. Although they valued the knowledge and clinical skills that older nurses had, it was stated that nurses must be upto-date and in their experience this was not always the case. Another respondent commented that the attitude of the older nurses to the employer and team environment was an important factor. "If they are engaged and up to date they are excellent team members, some are reluctant and this can impact on the team function".

\section{Additional strategies the Clinical/Charge Nurse Managers use to support older nurses}

Question Eight asked respondents if there were any further strategies they used to address issues facing older nurses in their clinical areas. The most prevalent strategies that emerged from this question related to: rosters, manual handling, engagement, relationship with the CNM, training and professional development, annual leave, night shift, hours of work and 
sick leave. Of note, however, was the fact that some of the "additional" strategies outlined by respondents had been presented to them in Question Five.

Rosters: Twenty five percent of respondents described careful attention to rosters as a strategy, offering flexibility and social rostering where able and paying attention to patterns (moving from day to night shift). One CNM outlined that she "tries to ensure they get the shifts that suit them best e.g. some prefer am's or pm's and I facilitate part time work for those that want it". Another commented, "I try to accommodate their preferred shifts on the roster where ever possible, I try not to overload them with extras and always being preceptors". One CNM observed that although there is legislation to support flexible hours in the context of a 24-hour 7day a week service, with constant staffing issues this was incredibly difficult.

Manual handling/Workload considerations: Twenty percent of respondents described careful attention to manual handling in the clinical environment as a strategy. Ensuring that there was enough equipment and training to reduce injury and support older nurses was mentioned by a number of respondents. One respondent commented, "I am vigilant with manual handling training". Attention to workload intensity was also discussed. Ensuring appropriate allocation and employment of health care assistants to support and carry out non nursing duties was also raised by respondents. One CNM commented that she "employs more Health Care Assistant (HCA) to do the non nursing tasks" with another outlining that attention is given to "rotation through heavier work areas". Another commented that "I am more mindful of heavy workloads and ensure they have the support to manage them".

Engagement: Keeping older nurses engaged was a strategy discussed. Twenty percent of respondents used encouragement to attend courses or conferences to maintain interest. One CNM outlined that she "really encouraged participation in quality projects, I try and find an area that they excel in and provide opportunities in supporting them to be champions". 
Relationship with the CNM: Ten percent of respondents discussed the importance of knowing staff personally, listening actively to their needs and ensuring they felt respected and valued in the workplace. One CNM outlined her approach as "keep it simple, I look after them they can do their job, I am doing mine". Another commented, "I ensure they know I am listening to their concerns and celebrations and that they feel supported by myself and all staff". Another described that she used "active listening skills to listen to them and address their individual needs".

Training and professional development: Acknowledgement of the different learning styles older nurses may have, and support with concepts that may be new to them, featured in the responses around training and ongoing professional development. Of respondents, $10 \%$ outlined the attention they gave to support older nurses, particularly around information technology (IT) and continuing competency requirements both internally with Professional Recognition Development Programmes (PDRP), and externally with requirements under the HPCA Act (2003). One CNM described "I provide active support with the PDRP process and how to meet the criteria". Another commented that "I provide encouragement to attend training and actively support them with new skills e.g. IT, with an approach that is non threatening and supportive".

Annual leave: Ten percent of respondents monitored and encouraged older nurses to take regular annual leave. This was described as a strategy to help older nurses manage work intensity. One CNM commented that "I support the use of Annual leave to give longer breaks (days off)". Another commented that "I have an increased awareness of regular annual leave planning".

Night shift: Ten percent of respondents stated that the older nurses in their area did not do night duty, some had permanent night staff. One CNM chose to employ older nurses casually so older nurses could work flexible shifts. She had observed that "many of the nurses over 50 have found they are unable to work night shift due to physiological effects and 
increased trouble sleeping, the ability to employ casually allows them the chance to achieve work/life balance".

Hours of work: Encouraging and supporting older nurses to reduce their full time equivalent (FTE) work was a strategy that was discussed by $8 \%$ of respondents. One CNM commented that older nurses in the ward were better able to manage the intensity of work if they worked a reduced FTE.

Sick leave: Eight percent of respondents commented on the use of sick leave to support older nurses, with one CNM suggesting that older nurses should have unlimited sick leave, for "wear and tear" related issues. A common theme emerging around sick leave was the support for domestic leave for care of aging parents, grandchildren and spouses.

Ten percent of the respondents reported that they had no specific strategies for older nurses, that they considered all their staff's needs equally. One respondent discussed that supporting older nurses sometimes put pressure on other staff, particularly around night shift and workload allocation. One CNM commented that "the very mature $R N$ does not do nights - this has created problems as it is seen as not doing her fair share".

\section{General comments}

At the end of the questionnaire opportunity was provided for any further comments. Just under half of the respondents, $46 \%$ ( $n=37)$ added further comments with some taking the time to add significant commentary. Five main themes emerged from the comments: needs of all staff, resistance to change, generational tension, organisational support and work intensity.

Needs of all staff: A quarter of respondents commented that there was a need to look after all staff. As one CNM commented, "I think the strategies you have suggested apply to nurses of any age". Attention to workforce development and growing our own in preparation for the retirement of the older nurses was also raised by one respondent. "I believe we need to foster the new grads and work at retaining them to build the workforce from the bottom up. The older nurses will eventually retire, we need to 
prepare for that." The mix of the team was also raised as an important point, some commenting that the balance of the team with a mix of young and old was important and that all members must be valued and treated fairly. One CNM commented that "a good mix of ages is good, everyone learns from each other - must value all".

Resistance to change: Of respondents, $20 \%$ took the opportunity to comment on the difficulties they faced with some of their older nurses in the changing health care environment. However, most took care to be clear that it was some, not all. Resistance to change and reluctance to participate in programmes such as PDRP proved challenging to some, and motivation to be at work was also described as a challenge. One CNM commented that financial pressures and not wanting to be nursing any more but feeling like it was too late to retrain meant that some nurses were not there for the right reasons and were reluctant to engage and be active members of the team. Another CNM, when describing the tension she faced, commented that "some (as in most) nurses are remarkable and so valuable to the hospital, I never want them to retire but other nurses can make life very difficult unless managed with tact and accountability".

Generational tension: This links to the needs of all staff but several respondents took the time to comment on the generational tension that existed in their workplace. One CNM commented that before she could support the team, learning for her took place as "being an older nurse myself has caused some frustrations until I understood the $X \& Y$ generation differences, which need quite a different approach". Another CNM commented that "some older nurses are intolerant of the ' $Y$ ' generation. It must be recognised that the ' $Y$ ' generation find the older nurses a challenge too". The skill required in managing the generational tensions was described by one respondent. "It is a skill and a challenge to the CNMs and the rest of the staff to ensure they understand each other's preferences and function as a team - not always easy." 
Work intensity: How to help older nurses manage the pace and intensity of the health care environment was raised by a small number of respondents, commenting that they saw their staff sometimes really struggling with short staffing and the heaviness of the workloads. As one CNM commented, "a vital workforce - need to be looked after but need strategies for replacement and not 'flog' them while they are still working".

Organisational support. Support for the CNMs from senior management was discussed by several respondents. Removing barriers to innovation with rostering and flexible hours needed organisational support, and as one CNM commented, even national strategies to support innovation. Reducing the number of night shifts and fair and equitable access to training were also raised as something the organisation needed to support as a whole.

The responses of the participants aged over 50 years and those aged less than 50 years were broadly compared. There was little discernable difference in the type of response. Apart from a slightly higher response rate from DHB 2 there was also little discernable difference between the two DHBs surveyed.

\section{Summary}

The questionnaire was well answered and respondents took the time to enrich the data collected with expansive and well thought out commentary in the open questions. There was a significant response rate to the questionnaire (84.5\%) indicating that this was an area of relevance for the respondents. These findings represent the views of two large groups of CNMs on the issues relating to the retention of the older nurse in the workplace, and in a New Zealand context relate to similar findings overseas. The results will be discussed in the next chapter within the context of the literature review. 


\section{Chapter Five: Discussion}

\section{Introduction}

The aim of this research was to explore from a New Zealand perspective, the level of awareness the CNM group had of the issues facing older nurses in the workplace, and to explore with them strategies to addressing those issues. The participants were two groups of CNMs from two DHBs in New Zealand. The response rate was significant for a postal survey (84.5\%) and in addition to the closed questions the questionnaire elicited rich data from the open questions. Just under half the CNM respondents $(43 \%)$ were themselves aged over 50 years. Formal comparative analysis of the responses of those aged over 50 years with those of respondents aged less than 50 years was not undertaken, but broad comparison showed little discernable difference. This chapter will discuss the findings in relation to the literature. Five main themes emerged from the literature: the future health workforce, retention of older nurses, age discrimination and the older nurse, generational tension and line manager behaviour and retention. The findings from the research were consistent with these themes. This chapter integrates the research findings and the literature in a discussion focusing on three facets: environment, engagement and relationships.

\section{Environment}

Understanding the impact of the environment in which the older nurse works is a key process when considering retention. The term environment is used to encompass the wider context in which the older nurse practices. It is well documented that an environment that pays attention to rostering, shift work, work intensity and manual handling is more likely to retain older nurses (Andrews et al., 2005; Camerino et al., 2006; Cyr, 2005; Fitzgerald, 2007; Hader et al., 2006; Letvak, 2003). The concerns about the future nursing workforce and the retirement of this cohort of nurses are being widely discussed in the literature, and raised at national level in New Zealand by those involved in nursing workforce issues (Alpass \& Mortimer, 2007; DHBNZ, 2008). This concern was reflected in the study 
group with $89 \%$ of respondents identifying that they strongly agreed or agreed with the statement: 'If we don't address the issues facing older nurses this will have a major impact on the nursing workforce'. However, as with similar findings overseas in relation to a specific organisational policy for retention of older nurses (Letvak, 2002a; McHaney \& Varner, 2006) this research found that $92 \%$ of respondents were not aware of any specific organisational policy that existed to address the needs of an older nursing workforce. One DHB was my own place of employment at the time of the survey and I could confirm that there was no specific policy in place to guide the CNMs to meet the needs of older nurses. The Director of Nursing of the other DHB surveyed confirmed that they also did not have specific policy in place (S. Hayward, personal communication, 2009). This perhaps suggests that little is being done at either a national or organisational level to actively create an environment that retains older nurses.

From the findings, the attempt to provide an environment that is conducive to retaining older nurses was apparent. The suggested retention strategies put forward in the questionnaire that were seen by respondents as the most helpful were improved manual handling devices (98\% agreed), part time hours and flexible shifts ( $97 \%$ agreed), and flexibility with rosters (90\% agreed). In open ended questions respondents also mentioned strategies such as providing flexible rostering, encouraging and supporting part-time hours and encouraging regular annual leave. This was often mentioned in relation to attempting to reduce work intensity and assist the older nurse to manage the pace and 'heaviness' of the clinical environment. For example, one respondent commented that "I am more mindful of heavy workloads and ensure they have the support to manage them". Other strategies respondents suggested included providing enough manual handling equipment and using health care assistants to assist with non-nursing tasks. Some CNMs also outlined that they take care when allocating patients to ensure the older nurse had a manageable workload. Night shift for older nurses was also raised as an issue with some respondents indicating that older nurses did reduced or no night shifts. 
One CNM commented that "many of the nurses over 50 have found they are unable to work night shift due to physiological effects and increased trouble sleeping". The strategies discussed by the CNM group appeared to be informal and individual in approach. This is supported by $92 \%$ identifying that they were not aware of any formal policy within their organisation that specifically addressed the needs of an older nursing workforce. A consistent theme throughout the strategies offered by the CNM respondents was the constant need to balance the needs of the older nurse with the rest of the staff. This is an important point. This research focuses on the older nurse, but they cannot be viewed in isolation. To support the CNMs and promote acceptance within the wider team, organisational support is needed with their informal strategies. One CNM commented that although there is legislation to support flexible hours in the context of a 24 hour 7 day a week service, with constant staffing issues this was incredibly difficult.

Fitzgerald (2007) raised the concept of aging in place, which is providing an environment that encourages and supports older nurses. Respondents reported that they encouraged older nurses to take regular annual leave and reduce their hours to help them manage the work intensity, and $98 \%$ of respondents strongly agreed or agreed that improved lifting and handling devices would be a good idea. Issues raised by respondents in relation to balancing the needs of the wider team with supporting the older nurses represent a picture of CNMs using strategies to support older nurses in isolation with little organisational policy or support. If we are to retain the knowledge and experience of the older nurse in the practice areas a more co-ordinated approach would seem prudent. Mion et al. (2006) support a co-ordinated approach at an organisational level suggesting valuable knowledge and wisdom can be retained within an organisation. The older nurse can, with support, move to other practice areas within an organisation. This ensures the nurse continues to feel valued and the organisation retains an experienced nurse. 


\section{Engagement}

Engagement is an active process and involves both the employee and employer. An employee who is engaged contributes in meaningful ways to the workplace. The value of older nurses was clearly articulated by respondents. The respondents overwhelmingly described positive attributes when asked what they saw as the strengths of the older nurse. When asked what additional strategies they used to support older nurses they provided thoughtful and considered responses demonstrating a wide range of strategies. But what started to emerge was the use of qualifying phases, such as "most older nurses", "usually loyal" and "some older nurses". The general comment section was elicited frank responses when describing the challenges the CNM group sometimes faced with the older nurse. Some challenges described included managing the older nurse who was disengaged, not interested in participating in training or ongoing professional development, or at work due to financial pressures. Some CNM respondents described that when dealing with a sometimes negative attitude from older nurses they felt that some were there waiting to retire, no longer wishing to contribute to the team. This situation was reported to be very challenging and sometimes destructive to the team as a whole. Also described as a common challenge was resistance to change and an unwillingness to try new things.

The quality of relationships and the environment all contribute to engagement (Cohen, 2006). However, finding a way to ensure the older nurse continues to feel valued and engaged is an ongoing challenge that was identified by respondents and in the literature (Cohen, 2006; Fitzgerald, 2007; Hatcher et al., 2006; Letvak, 2002b). If an older nurse is disengaged from the work environment, the response required is surely a shared one with due consideration given to the quality of the environment in which the older nurse is working. Returning to the generational context of the older nurse, which is a context of loyalty and hard work, their self worth is closely aligned to their work ethic (Wieck, 2007). If an older nurse no longer feels valued, if age discrimination is tolerated in the workplace and the younger generation are more valued for formal academic success 
rather than clinical and life experience, reasons for disengagement may be very apparent.

The role of the CNM is again a crucial one when considering engagement of older nurses. Hader et al. (2006) describe that attention to appropriate ongoing training and professional development is crucial to engaging staff. Not all adults learn the same way and, when considering the different learning styles of four generations in the workplace, it is unlikely that one approach will suit all (Hu et al., 2004). Some strategies outlined by the respondents to address this included providing extra support with new concepts, particularly in relation to information technology, and some described providing support with internal and external competency requirements. Another strategy outlined was finding a project or a role where the older nurse could excel and be a clinical champion, such as infection control. Further engagement strategies discussed in the literature include using older nurses to mentor younger nurses (Fitzgerald, 2007). However, when this strategy was explored with the CNM group $61 \%$ agreed, $31 \%$ were undecided and $8 \%$ disagreed. Further comment was not sought by the questionnaire but some comments from respondents related this to generational tension being a possible barrier to some older nurses mentoring younger nurses. "Some older nurses are intolerant of the ' $Y$ ' generation. It must be recognised that the ' $Y$ ' generation find the older nurses a challenge too." Support from an organisational perspective is discussed in the literature as a strategy to reduce age discrimination and increase generational awareness for all workers. Wallis (2009) goes as far as to assert that managers and organisations should work to provide a culture of understanding and tolerance which is a key retention factor for the older nurse.

\section{Relationships}

The quality of the relationships an older nurse has with the organisation, line manager and peers is a major driving influence of job satisfaction and intention to stay in the workplace (Cohen, 2006; Hatcher et al.,2006; Mion et al., 2006). Retention of the older nurse is reported to be a shared 
responsibility, and this was reflected by $43 \%$ of respondents in this study. Despite this the most crucial relationship is that between the older nurse and the line manager. Hu et al. (2004) describe a nurse's manager as the filter through which legislative and organisational policy and process is passed through to the nurses at the bedside. This analogy is important as, despite governmental legislation and policy around age discrimination and positive aging strategies, the person who will set the tone for the environment in which the older nurse works is the CNM. Ensuring the environment is one that does not tolerate ageism is an important factor. The CNM's own view of ageism will influence the older nurse and other team members. The myths that older workers are set in their ways and not able to easily adapt are often perpetuated by the older nurse and their peers (Alpass \& Mortimer, 2007). Other views held surrounding declining physical and mental capabilities, poor interpersonal skills and increased sick leave also exist (Hatcher et al., 2006). Yet these are disputed by Letvak (2002b) who argues that chronological age is a weak predictor of performance that the older worker is adaptable and when comparing sick leave, older and younger workers have very similar levels. The CNM has the potential to make age discrimination unacceptable and be a positive role model, but they must have the adequate support, training and preparation to do this successfully, and the organisation must set the direction to support this. Andrews et al (2005) discuss the relationship between what is governmental and organisational policy regarding the older worker as being nothing more than rhetoric. The research findings would support this as $92 \%$ of respondents were not aware of any specific organisational policies that existed to support the older nurse. This response is reflected in similar North American studies (Letvak, 2002b; McHaney \& Varner, 2006).

If the organisation does not set the policy direction to support the older nurse, it is likely that the CNM will find it difficult to effectively support the older nurse in the workplace. Study findings suggest that the CNMs as a group work very hard to retain the older nurse despite the apparent lack of organisational policy direction. Although the CNMs described informal and 
individual approaches to retaining older nurses, a common theme that emerged was the importance of developing relationships with the older nurses in their areas. One respondent summarised her approach to effective relationship building as "I ensure they know I am listening to their concerns and celebrations and that they feel supported by myself and all staff". Another commented that "I use active listening skills to listen to them and address their individual needs".

The relationships older nurses have with their peers also came through the responses, and managing the generational tensions that exist was identified as one of the strategies that the CNMs used to support the older nurse. Reference to generational tensions was consistently made by CNMs despite the absence of specific questions about generational issues. Crumpacker and Crumpacker (2007) suggest caution when focusing on the perceived issues of a multigenerational workforce and the danger of stereotyping exists. But they further suggest an understanding of this can support the development of a workforce culture that understands the different needs of its members. The CNM respondents reinforced this view and discussed that a shared understanding of the different generational needs was important to the wider team and that this understanding needed to come from the older nurse as well. One respondent commented that "it is a skill and a challenge to the CNMs and the rest of the staff to ensure they understand each other's preferences and function as a team - not always easy". Crumpacker and Crumpacker (2007) suggest that each generation has "observable characteristics" and that these relate to "ethics, work-life balance, authority and leadership and technology". In relation to the generation of the older nurse, those from the silent and baby boomer generation are likely to be loyal employees if they are valued for their practice wisdom. From the CNM responses, fostering a culture of understanding and valuing the older nurse is seen as an important strategy.

The word "value" is woven throughout the questionnaire responses and published literature. The older nurse comes from a generational context of loyalty and hard work, where their self worth is closely aligned to their 
work ethic (Wieck, 2007). When asked what strengths older nurses brought to the workplace, the CNM respondents used words such as knowledge, wisdom, life/clinical experience, strong work ethic, loyalty, maturity and stability. The word value was used in relation to the qualities described. Older nurses themselves describe feeling valued as extremely important to their job satisfaction. The literature would suggest that the older nurse does not always feel valued (Cohen, 2006; Fitzgerald, 2007; Hatcher et al, 2006; Letvak, 2003). This suggests that preconceived ideas about older nurses, along with the impact of a manager's behaviour, are a significant influence on how an older nurse views her value to the organisation. Ensuring older nurses felt valued was identified by some of the CNM respondents as important, and responses demonstrated that they gave attention to this. Although some indicated this was not always easy, one respondent suggested that the way staff were recognised through measurable achievements like internal competence assessment frameworks (such as PDRP and formal post registration qualifications), rather than recognising years of clinical experience and achievement, was inherently suggesting that one was more valuable than the other.

\section{Summary}

This chapter provided an insight into the world of the older nurse and the complexity of the CNM role. The selection, skill and support of the CNMs to enable the provision of an environment that fosters positive relationships and ensures an engaged workforce cannot be underestimated in relation to the retention of the older nursing workforce. Whilst legislation and policy may be set at a national level, if it is not enacted at an organisational policy level with formal support for the CNM, retention of the older nurse is heavily reliant on an individual CNM's understanding and personal skill. The study identified that the strengths an older nurse brings to the clinical environment are valued by the CNMs, yet the relationships and environment can negate or limit the older nurse's perceived value, leading to disengagement in the workplace. 
If the health sector is truly concerned with retaining the knowledge and experience of the older nurse throughout the next two decades, the sector as a whole must work in a co-ordinated way at a national level to support organisations to assist the CNMs to undertake recognised strategies to improve retention of older nurses. The following chapter will outline potential strategies and recommendations from the study findings and literature, along with limitations of this research and suggestions for future research. 


\section{Chapter Six: Limitations, Recommendations and Conclusion Introduction}

This research sought to discover the level of understanding amongst CNMs in relation to the retention and support for older nurses in a New Zealand context. The predictions for the future New Zealand health care workforce over the next 10 to 20 years, as the baby boomers retire, suggest that a significant challenge to the health care environment lies ahead. Retaining our current health workforce including older nurses with valuable experience is an important short to medium strategy to bridge the potential workforce shortages. The role of the CNM in relation to retention of the older nurse in particular is recognised to be important. This study utilised this important group in an attempt to gain an understanding of their awareness of the issues relating to the older nurse and to identify strategies they employed in regards to retaining the older nurse in their workplace. This study identified that the CNM group were aware of the issues facing older nurses, and were using strategies aimed at supporting the older nurses, on a mostly informal and individual basis. Findings from this study could be used to inform a more national coordinated approach to retention of the older nurse to support the future health workforce environment.

\section{Limitations}

On reflection and following data analysis there were areas where the study could have been strengthened. However, the respondents, answers in the pre-test did not suggest these needed to be changed, nor did those respondents suggest it in their feedback. Question One asked respondents to estimate the percentages of nurses in their areas aged over 50 years. Groupings could have been presented to narrow the range of responses, as the range made data analysis difficult. Of the options presented to respondents in Question Two, two similar options were presented: some awareness and somewhat aware, a better choice may have been some awareness and little awareness. Question Seven sought respondents' views on the strengths of older nurses, not areas of 
weaknesses or challenges. Perhaps as a result of this, participants used the open-ended questions as an opportunity to discuss the weakness or challenges they faced with the older nurse. This, however, did allow this aspect to be addressed in the study. I selected two practice areas in one type of health care setting (large tertiary hospitals). It may have provided more transferability of findings to have used smaller less acute practice settings or aged care providers. Nevertheless this study does provide an overview of CNMs' understanding of the older nurses within the large tertiary hospital setting.

The research yielded an excellent response rate (84.5\%) from approximately $15 \%$ of the national total of CNMs working in District Health Boards in New Zealand. This therefore provided a reasonably reliable sample, evidence from which can be used to generalise findings to the larger CNM group. Although this is a small and relatively descriptive study it does provide an overview of the topic and from a CNM point of view, provide insight into the issues facing older nurses in New Zealand and the strategies CNMs are using to support and retain the cohort of older nurses

\section{Implications for practice}

The premise for this study is that retention of the older nurse may be an important short to medium term strategy to address the predicted future health workforce shortages. The understanding of the issues facing older nurses in the New Zealand healthcare environment and what strategies may assist in retention is not well described at a national level. The CNM is a pivotal person in relation to retention of the older nurse and it would appear, often working to support and retain older nurses on an informal and individual basis. A more coordinated national approach to identified strategies aimed at support and retention of older nurses is suggested. Implications and suggested approaches are outlined below in relation to: organisational policy, CNM support, education for generational understanding and age discrimination, health and safety and work intensity and value of older nurses. 
Organisational policy: The existing literature and study findings would suggest that there is a lack of organisational policy to specifically support the older nurse in the workplace. Whilst CNM respondents were very aware of the needs of the older nurse and also discussed a number of strategies they used to support older nurses, 92\% stated that they were not aware of any specific organisational policy in their areas to support the older nursing workforce. Setting clear policy and direction in relation to supporting the older nurse could enable the CNM to provide the support in a manner that is clear and transparent to the wider healthcare team. As employers, consideration must be given to the strategies identified and clear direction and support given to the nursing leaders who are the most influential on retention. As a profession, nursing is in a position to take action to support the older nurse to stay in practice. A lack of co-ordinated response may mean we are at risk of losing valuable experience and knowledge prematurely from what will be a rapidly reducing health workforce. I would recommend that organisations that employ nurses and professional groups who support the nursing workforce actively consider the retention of older nursing workforce. Retirement of a significant portion of our nursing workforce is underway and however widely discussed meaningful co-ordinated action to retain this workforce appears to be lacking.

CNM support: It has been clearly identified from the literature that the nurse's line manager (in the context of this research the CNM) is extremely influential in relation to retention of the older nurse. This position is the role model for the environment in which the older nurse practices, therefore having the right person with the appropriate skill set and support is crucial. Anthony et al. (2005) suggest that although line managers are aware of the importance of providing a positive supportive environment, the pressure of day-to-day or even minute-to-minute decision making and unexpected issues take priority. Pressure from organisational requirements may also lead to an inability to adequately provide support to the staff. Cohen (2006) discusses the importance of organisations ensuring that they are providing the appropriate level of support to the line 
managers so that they can do their job well, recognising that if they are forced to balance multiple responsibilities it is the support to their staff that suffers. Having the right person in these pivotal roles is the first step. Careful attention to recruitment and then providing ongoing support to CNMs is a key responsibility of nursing management. Staff turnover rates and exit interviews should be monitored to provide information on the clinical environment the CNM is providing. I would recommend that organisations have a responsibility to ensure that the environment does not place unrealistic expectations on the role, that they are enabled to give attention to supporting their staff and that the CNM must undertake appropriate ongoing professional development to continue to grow in the role.

Education for generational understanding and age discrimination: Developing a culture of understanding and respect is an important part of an organisation that wishes to retain staff. Suggested ways of developing this include providing education to staff on generational diversity (Piktialis, 2007). When discussing strategies to prevent ageism and promote generational tolerance, Letvak (2002b) suggests education should begin at school and be included in undergraduate programmes. Some of the respondents surveyed suggested that this understanding must work both ways, and the older nurse must be supported to understand the other generations as well. If an environment is to support and retain an older nurse, it must demonstrate effective leadership from an organisational perspective, one that sets direction for an understanding of generational diversity and intolerance of age discrimination. I would recommend that organisations give consideration to how education for staff on generational diversity and age discrimination can be incorporated.

Health and safety and work intensity: Strategies identified both in the literature and by respondents included ways to support the older nurses to manage the intensity of the clinical environment. Fitzgerald (2007) suggests that attention is given to provide an environment that saves physical energy and prevents injury. Attention to allocation of heavy patients, ensuring that there is appropriate equipment to assist with 
manual handling and providing an appropriate amount of non nursing assistance are strategies to support older nurses. Support from the organisation to allow flexibility with rosters and innovation with leave management would support older nurses and CNMs in trying to balance the needs of the wider team. Organisational and human resource guidelines for line managers regarding the promotion of health and safety issues and acceptable methods to reduce work intensity for older nurses could provide much needed support for the CNM in this regard.

Value of older nurses: Feeling valued is a key retention factor for older nurses and again the most influential person is the nurse's line manager (Letvak, 2003). Seeking ways to ensure the older nurse continues to feel valued and remains an actively engaged employee is a shared responsibility, in which the organisation and the CNMs must find ways to ensure the older nurses years of clinical experience and achievement is recognised.

\section{Future research}

This is an important topic that has not been previously explored from a New Zealand perspective. Further research within the health care sector would be valuable in order to establish older nurses' perspective, existing policy and direction of organisations and the perspectives of education providers in relation to retention of older nurses. Further exploration of the topic in different clinical settings such as aged care or primary health care may also add value from a future workforce perspective. Exploration of these issues would add to the body of knowledge in relation to this topic and has the potential to guide and inform future workforce planning.

\section{Conclusion}

During this research journey my professional career path has seen me move to a senior nursing leadership role and I now have a much broader overview of the healthcare sector particularly in relation to current and future workforce retention and recruitment. The loss of a significant portion of the nursing workforce over the next 10 to 20 years is a threat and yet my own experiences evoke a concern that efforts to actively respond to 
retain older nurses in the workforce are poorly coordinated and seen by some as unnecessary. The healthcare sector has a responsibility to ensure that we retain our valued members of the workforce for as long as is feasible. The retention strategies outlined in this thesis are not complicated but they do require organisational direction and support if they are to be effectively implemented. This study also highlights the importance of the nurse's direct line manager in relation to retention. The organisation must ensure that the right people with the right preparation are undertaking these pivotal roles and that ongoing support and development is occurring.

This was a small study with recognised limitations. Nonetheless the provision of previously unknown data has contributed to the knowledge in relation to retention of the older nurse in a New Zealand context. The findings challenge the apparent sense of complacency concerning our future nursing workforce and indicate that remedial action to support the older nurse in the workplace in order that clinical experience and practice wisdom are not prematurely lost. 


\title{
Appendix A: Questionnaire
}

\section{VICTORIA UNIVERSITY OF WELLINGTON}

Te Whare Wānanga o te Ūpoko o te Ika a Māui

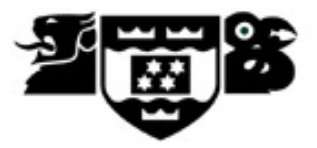 \\ GRADUATE SCHOOL OF NURSING, MIDWIFERY \& HEALTH \\ Research paper: 594 Thesis \\ Sam Powell - MA (applied) Nursing student \\ Email: $\gg \gg \gg \gg \gg \gg \gg$
}

Survey Questionnaire

Please complete and place in the envelope provided and return to $>>>>>>$ by Friday $1^{\text {st }}$ August

1. What percentage of nurses do you estimate in your ward/clinical area to be aged 50 years and over?

2. How aware are you of the needs of the older nurses in the workplace? Please circle:

Very aware Some awareness Somewhat aware Not aware at all

3. Are you aware of any specific policies within your organisation to address the needs of an older nursing work force

Please circle:

Yes No

4. Who is responsible for assisting older nurses to stay in the workforce?

Please select (more than one may be selected)

i) The Nurse themselves 
ii) The Charge Nurse Manager

iii) The Employer

Iv) The Government

5. Below are some strategies that have been suggested to address the needs of an older nursing workforce: Please indicate your opinion on the usefulness of each strategy

Please circle

Increased flexibility with rostering

Strongly agree Agree Undecided Disagree Strongly disagree

Improved lifting and handling devices

Strongly agree Agree Undecided Disagree Strongly disagree

Consideration of the environment including flow of the ward and lighting

Strongly agree Agree Undecided Disagree Strongly disagree

Part time hours and flexible shifts

Strongly agree Agree Undecided Disagree Strongly disagree

Start superannuation after the age of 60 to supplement part time work

Strongly agree Agree Undecided Disagree Strongly disagree

Older nurses utilised to orientate younger nurses

Strongly agree Agree Undecided Disagree Strongly disagree

Increased professional development opportunities

Strongly agree Agree Undecided Disagree Strongly disagree 
6. If we don't address the issues facing older nurses this will have a major impact on our nursing workforce

Please circle:

Strongly agree Agree Undecided Disagree Strongly disagree

7. What strengths do older nurses bring to the nursing workforce?

Please comment:

8. Are there any further strategies you use to address issues facing older nurses in your clinical area?

Please comment:

9. How long have you been a Clinical Charge Nurse/Charge Nurse Manager?

Please select:

Under 5 years

$5-10$ years

$10-15$ years

$15-20$ years

Over 20 years

10. What is your own age?

Please select:

$25-35$ years

$35-40$ years

$40-50$ years

50 or older

Any further comments?

Thank you for taking the time to complete this questionnaire

Please return completed questionnaires to >>>>>>>>> in the envelope provided 


\title{
Appendix B: Permission to use/ and or adapt survey tool
}

\author{
Hi Samantha
}

How wonderful you are interested in studying older nurses also! SO IMPORTANT of a topic. I have continued to speak/present on the issue and I consult with hospitals throughout the USA to help them change their treatment of older nurses. I hope I am making a difference! You are more than welcome to use any/all my questionnaire materials- I have attached the survey I used for my study on health/safety of older nurses - feel free to use/adapt. My study on job productivity and older nurses is currently under review-I am sharing it with you as 'in review' for your use - I hope it is in print soon (Nursing Economics is reviewing it).

Please let me know if I can be of more assistance. Best wishes as you complete your masters studies!

Susan

Susan Letvak PhD, RN

Associate Professor

Community Practice Department

-----'Sam Powell' Samantha.Powell@>>>>>>>>.New Zealand> wrote: -----To:

<Susan_Letvak@>>>>>>

From: 'Sam Powell' <Samantha.Powell>>>>>>>> New Zealand>

Date: 08/26/2007 08:17PM

Subject: Research and the older nurse

Hello Susan

I am a post graduate student studying at Victoria University in New Zealand, I am currently developing a research proposal and hope to undertake my thesis next year to complete my Masters. The path I have chosen has been greatly influenced by your work, I reviewed your article The Experience of Being an Older Staff Nurse for a journal club a few years ago and this has become a focus of interest for me, as in the US, New Zealand has an aging nursing workforce and we have been slow to respond to the needs of the older workforce.

I am interested in raising awareness of the issues facing older nurses in the New Zealand nursing workforce and have undertaken a literature review to develop my research proposal, the survey you undertook in 2002 designed to determine knowledge base and plans for the aging workforce is of interest to me and I would be interested in using a similar set of questions in my current practice area. With appropriate acknowledgement of source, would you have any objections to me adapting some of your questions for my survey? The other question I had was related to a topic that you supervised in 2004 2005, the pilot test of an instrument to measure job stress, job related injury, work productivity and intent to stay in older nurse. Has this been published any where?

Thank you for taking the time to consider my request and I look forward to your response Regards

Sam Powell 


\title{
Appendix C: Covering Letter to Applicants
}

\author{
VICTORIA UNIVERSITY OF WELLINGTON
}

Te Whare Wānanga o te Ūpoko o te Ika a Māui

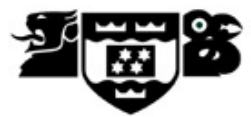

\section{GRADUATE SCHOOL OF NURSING, MIDWIFERY \& HEALTH}

Research paper: 594 Thesis

Sam Powell - MA (Applied) nursing student

Email: >>>>>>>>

Participant information sheet

I am a Master of Arts (Applied) Nursing student at Victoria University of Wellington. As part of this degree I am undertaking a research project leading to a thesis. I am a registered nurse with a strong interest in professional development and supporting the nursing workforce in practice. The average age of a nurse in practice in New Zealand (New Zealand) is 45 years. In New Zealand we are facing a health workforce shortage, one that is predicted to worsen over the next 10 to 20 years. I am interested in what we are doing to retain our current nurses in practice, with a particular focus on the older nurse (aged 50 years and over). Retention of this group of nurses has been studied internationally and has shown that there are key factors that keep these nurses at work. I am very interested to explore this at a national level.

The role of the Charge Nurse Manager (CNM) in any organisation is an important, one that provides leadership at a ward/service level to ensure quality health outcomes for the patients and their families/whanau. On a daily basis you are dealing with the impact of recruitment and retention issues, increased acuity and the performance of staff. As a CNM you are in a key position to influence an older nurses decision to stay in practice. I would like to obtain a snapshot of what your understanding is of the issues facing the older nursing workforce and to explore what strategies you use to deal with these issues on a daily basis. On completion of this project I hope to use the information to contribute to retention of this age group of nurses in our workforce. In order to collect the information required I am inviting you to participate in this research by completing and returning the questionnaire enclosed. This questionnaire is being sent to two groups of CNM, in similar size acute care hospitals in New Zealand. Your participation is appreciated and the questionnaire should take approximately 10 to 15 minutes to complete.

Participation in the study and completion of the questionnaire is voluntary. Information collected from the questionnaire will be confidential, it will not identify participants name or workplace so anonymity can be maintained. The information gathered will be handled only by myself or my supervisor and disposed of appropriately once the final research has been completed and assessed. Information from the questionnaire may be quoted or reported but the identity of the individual will remain anonymous

Thank you for your time

Sam Powell 


\section{Appendix D: Ethics Approval}

TE WHARE WĀNANGA O TE ŪPOKO O TE IKA A MĀUI

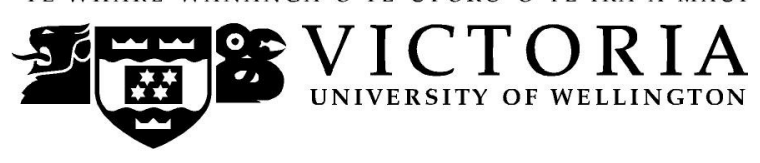

MEMORANDUM

Phone $\quad>>>>>>>$

Fax

>>>>>>>

\begin{tabular}{|c|c|}
\hline TO & Sam Powell \\
\hline $\begin{array}{l}\text { COPY } \\
\text { TO }\end{array}$ & Associate Professor Rose McEldowney \\
\hline FROM & Dr Allison Kirkman, Convener, Human Ethics Committee \\
\hline DATE & June 26, 2008 \\
\hline PAGES & 1 \\
\hline $\begin{array}{l}\text { SUBJEC } \\
T\end{array}$ & $\begin{array}{l}\text { Ethics Approval: No 15733, (Updated number 15823) The Older } \\
\text { Nurse in the Workplace: Retention or Retirement. }\end{array}$ \\
\hline
\end{tabular}

Thank you for your application for ethical approval, which has now been considered by the Standing Committee of the Human Ethics Committee.

Your application has been approved from the above date and this approval continues until 28 February 2009. If your data collection is not completed by this date you should apply to the Human Ethics Committee for an extension to this approval.

Best wishes with the research.

Allison Kirkman

Convener 


\section{References}

Aiken, L., Buchan, J., Sochalski, J., Nichols, B., \& Powell, M. (2004). Trends in international nurse migration: The world's wealthy countries must be aware of how the 'pull' of nurses from developing countries affects global health. Health Affairs, 23(3), 69-77.

Alpass, F., \& Mortimer, R. (2007). Department of Labour Ageing Workforces And Ageing Occupations: A Discussion Paper: 2-55.

Andrews, J., Manthorpe, J., \& Watson, R. (2005). Employment transition for older nurses: A qualitative study. Journal of Advanced Nursing, 51(3), 298-306.

Anthony, M., Standing, T., Glick, J., Duffy, M., Pashell, F., Sauer, M., et al. (2005). Leadership and nurse retention: The pivotal role of nurse managers. Journal of Nursing Administration, 35(3), 146-155.

Arnold, H. (2008). Time is running out. Occupational Health, 60(2), 14-16. Retrieved from CINAHL Plus with Full Text database.

Beanland, C., Schneider, Z., LoBiondo - Wood, G., \& Haber, J. (1999). Nursing research: methods, critical appraisal and utilisation. (1st ed.). Sydney, Austrailia: Mosby.

Bennett, J., Davey, B., \& Harris, R. (2009). Commitment expressions of nurses aged 45 and over: Organisational, professional and personal factors. Journal of Research in Nursing, 14(5), 391 - 401.

Botti, M., \& Endacott, R. (2006). Clinical research 5: Quantitative data collection and analysis. International Emergency Nursing, 16, 132-137.

Boynton, P. (2004). Hands-on guide to questionnaire research: Administering, analysing and reporting your questionnaire. BMJ, 328, 1372-1375.

Brillhart, B. (2007). Research insights. Rehabilitation Nursing, 32(4), 136-138.

Buchan, J. (1999). Still attractive after all these years? Magnet hospitals in a changing health care environment. Journal of Advanced Nursing, 30(1), 100-108.

Buerhaus, P., Donelan, K., Ulrich, B., Kirby, L., Norman., \& Dittus,R. (2005). Registered nurses perceptions of nursing. Nursing Economic\$, 23(3), 110143.

Burnard, P. (2003). Writing a qualitative research report. Nurse Education Today, 24, 174-179. 
Camerino, D., Conway, P., Van der Heijden, B., Estryn-Behar. M., Consonni, D., Gould, D., \& Hasselhorn, H. (2006). Low-perceived work ability, ageing and intention to leave nursing: A comparison among 10 European countries. Journal of Advanced Nursing, 56(5), 542-552.

Cofer, M. (1998) Nursing ethics: Collegiality and intergenerational differences. Virginia Nurses Today, 10(4) p.11.

Cohen, J. (2006). The aging nursing workforce: How to retain experienced nurses. Journal of Healthcare Management, 51(4), 223-244.

Coughlan, M., Cronin, P., \& Ryan, F. (2009). Survey research: Process and limitations. International Journal of Therapy and Rehabilitation, 16(1), 915.

Crocker Houde, S., \& Devereaux Melillo, K. (2009). Caring for an aging population. Journal of Gerontological Nursing, 35(12), 8-13.

Crichton, N. (2001). Principles of statistical analysis in nursing and healthcare research. Nurse Researcher, 9(1), 4-16.

Crumpacker, M., \& Crumpacker, J. (2007). Succession planning and generational stereotypes: Should HR consider age based values and attitudes a relevant factor or a passing fad. Public Personal Management, 36(4), 349-368.

Cyr, P. (2005). Retaining older hospital nurses and delaying their retirement. Journal of Nursing Administration, 35(12), 563-567.

Davey, J. (2003). Human capital issues in an aging workforce. Social Policy Journal of New Zealand, 20, 156-172.

Dennis, H., \& Thomas, K. (2007). Ageism in the workplace. Generations, 31(1), 84-89.

Department of Labour. (2009). Ageing workforce - A literature review of the forms of age discrimination: An economic perspective. Wellington, New Zealand: Author.

District Health Boards/New Zealand Nurses Organisation. (2004). Multi-employer Nursing Midwifery Collective Agreement (MECA). Wellington, New Zealand: Author

Employment Relations Act (2000). Retrieved March 13, 2010, from http://www.legislation.co.nz/act/public/2000/0024/latest/DLM58317.html?s earch=ts_act_employment+relations+act_resel\& $p=1 \& s r=1$ 
Fitzgerald, D. (2007). Aging experienced nurses: Their value and needs. Contemporary Nurse, 24(2), 237-242.

Fox, R., \& Abrahamson, K. (2009). A critical examination of the US nursing shortage: Contributing factors, public policy implications. Nursing Forum, 44(4), 235-244.

Graneheim, U., \& Lundman, B. (2003). Qualitative content analysis in nursing research: Concepts, procedures and measures to achieve trustworthiness. Nurse Education Today, 24, 105-112.

Hader, R., C. Saver., \& Steltzer,T. (2006). No time to lose. Nursing Management, 37(7), 23-29.

Hatcher, B., Bliech, M., Connolly, C., Davis, K., O'Neill-Hewlett, P., \& Stokley-Hill, K. (2006). Wisdom at Work: The importance of the older and experienced nurse in the workplace. The Robert Wood Johnson Foundation, 1-73, Retrieved August, 2008, from http://www.rwjf.org/pr/product.jsp?id=15867

Health Practitioners Competence Assurance (HPCA) Act (2003). Retrieved 12 August, 2007, from http://www.moh.govt.New Zealand/hpca

Health Research Council (2008). About Maori Health Research. Retrieved September 9, 2007, from http://www.hrc.govt.New

Zealand/root/Maori\%20Health\%20Research/About_Maori_Health_Resear ch.html

Human Rights Act 1993 No 82 (as at 01 October 2008), Public Act Retrieved March 13, 2010, from

http://www.legislation.co.nz/act/public/1993/0082/latest/DLM304212.html? search=ts_act_human+rights+act_resel $\& \mathrm{p}=1 \& \mathrm{sr}$

Hu, J., Herrick, C., \& Hodgin, K. (2004). Managing the multigenerational nursing team. The Health Care Manager, 23(4), 334-340.

Health Workforce Information Programme (HWIP). (2009). Current Status of the National Regulated Workforce 2009 Retrieved December, 2009, from http://www.moh.govt.nz/moh.nst/pagesmh/6795/\$File/current-statenursing.pdf

Kupperschmidt, B. (2006). Addressing multigenerational conflict: Mutual respect and care fronting as strategy. ANA Periodicals 11(2) retrieved September 15, 2009, from http://www.nursingworld.org/MainMenuCategories/ANAMarketplace/ANAP eriodicals/OJIN/TableofContents/Volume112006/No2May06/tpc30_31607 5.aspx\#Laschinger05 
Leaver, D. (2000). Survey research techniques. Radiation Therapist, 71(4), 364375.

Letvak, S. (2002a). Retaining the older nurse. Journal of Nursing Administration, 32(7/8), 387-392.

Letvak, S. (2002b). Myths and realities of ageism and nursing. Association of Operating Room Nurses. AORN Journal, 75(6), 1101-1107.

Letvak, S. (2003). The experience of being an older staff nurse. Western Journal of Nursing Research, 25(1), 45-56.

McHaney, D., \& Varner, J. (2006). Accommodating the needs of the aging registered nursing workforce. The Alabama Nurse, 33(3), 24-25.

Meates, D. (2007). New ways of working to respond to the future workforce challenges. Conference presentation, Workforce Action: Ready for the Future, Wellington, New Zealand.

Ministry of Health. (2006). Health Workforce Development, Retrieved August 12, 2009, from www.moh.govt.New Zealand

Ministry of Health. (2010). Clinical Training Agency nursing portfolio analysis: Nursing entry to practice 2006-2008. Wellington, New Zealand: Author.

Ministry of Social Development. (2001). Positive aging strategy, Retrieved November, 2009, from http://www.osc.govt.nz/positive-ageingstrategy/index.html

Mion, C., Colleta, H., Cap, M., Fusilero, J., Podmore, M., \& Szweda, C. (2006). Retaining and recruiting mature experienced Nurses: A multicomponent organisational strategy. Journal of Nursing Administration, 36(3), 148-154.

Nursing Council of New Zealand. (2010). The newsletter of the nursing council of New Zealand. Wellington, New Zealand: Author.

Norman, L., K. Donelan., Buerhaus,P., Willis, G., Williams, M., Ulrich, B., \& Dittus, R. (2005). The older nurse in the workplace: Does age matter. Nursing Economic\$, 23(6), 282-289.

NZNO/ DHBNZ. (2007). Designated Senior Nurses / Midwifes Job Endorsed Titles. Wellington, New Zealand: Author.

Polit, D., Beck, C., \& Hungler, B. (2001). Essentials of nursing research $\left(5^{\text {th }}\right.$ ed.). Philadelphia: Lippincott.

Piktialis, D. (2007). Adaptations to an aging workforce: Innovative responses by the corporate sector. Generations, 31(1), 76-82. 
Reineck, C., \& Furino, A. (2005). Nursing career fulfilment: Statistics and statements from registered nurses. Nursing Economic\$, 23(1), 25-30.

Roberts, K., \& Taylor, B. (1998). Nursing research processes: An Australian perspective. South Melbourne: Nelson Australia Pty Limited.

Rubenfeld, G. (2004). Surveys: An introduction. Respiratory Care, 49(10), 11811185.

Santos, S., Carroll, C., Cox, K., Teasley, S., Simon, S., Bainbridge, L., Cunningham, M., et al. (2003). Baby boomer nurses bearing the burden of care: A four-site study of stress, strain, and coping for inpatient registered nurses. JONA, 33(4), 243-250.

Sherrod, D. (2006). Strategies for retaining older nurses. Nursing Management. $37(10), 12-14$.

Statistics New Zealand: A guide to good survey design. Retrieved September 8, 2007, from www.stats.govt.New Zealand

Statistics New Zealand: Census New Zealand. Retrieved September 18, 2009, from http://www.stats.govt.New Zealand/Census.aspx

Statistics New Zealand: New Zealand in profile. Retrieved November 22, 2009, from http://www.stats.govt.New

Zealand/ /media/statistics/methods\%20and\%20services/New

Zealandip09/new-zealand-in-profile-2009.aspx

Steinhauser, K., \& Barroso, J. (2009). Using qualitative methods to explore key questions in palliative care. Journal of Palliative Medicine, 12(8), 725-730.

Upeinecks, V. (2003). Recruitment and retention strategies: A magnet hospital prevention model. Nursing Economics, 21(1), 7-13.

Veale, B. (1998). Questionnaire design and surveys. Australian Family Physician, 27(6), 499-502.

Wagstaff, P. Surveys. In Cluett, E., \& Bluff, R. (Ed.), Principles and practice of research in midwifery (pp. 58-78). London: Balliere Tindall.

Wallis, L. (2009). Born to be different. Nursing Standard, 23(33), 62-63.

Watson, R., Manthorpe, J., \& Andrews, J. (2003). Older nurses and employment decisions. Nursing Standard, 18(7), 35-40.

Wieck, L. (2007). Motivating an intergenerational workforce: Scenarios for success. Orthopaedic Nursing, 26(6), 366-371. 